\title{
Objective Reduction in Many-Objective Optimization with Social Spider Algorithm for Cloud Detection in Satellite Images
}

Rachana Gupta ( 2015rec9517@mnit.ac.in )

Malaviya National Institute of Technology https://orcid.org/0000-0002-9717-2006

Satyasai Jagannath Nanda

Malaviya National Institute of Technology

\section{Research Article}

Keywords: Social spider optimization, remote sensing, cloud detection, objective reduction, manyobjective optimization

Posted Date: September 27th, 2021

DOI: https://doi.org/10.21203/rs.3.rs-917187/v1

License: (c) (i) This work is licensed under a Creative Commons Attribution 4.0 International License.

Read Full License

Version of Record: A version of this preprint was published at Soft Computing on January 10th, 2022. See the published version at https://doi.org/10.1007/s00500-021-06655-8. 


\title{
Objective Reduction in Many-Objective Optimization with Social Spider Algorithm for Cloud Detection in Satellite Images
}

\author{
Rachana Gupta · Satyasai Jagannath Nanda
}

Received: date / Accepted: date

\begin{abstract}
An important difficulty with multi-objective algorithms to analyze many-objective optimization problems (MaOPs) is the visualization of large dimensional Pareto front. This article has alleviated this issue by utilizing objective reduction approach in order to remove non-conflicting objectives from original objective set. The present work proposed formulation of objective reduction technique with multi-objective social spider optimization (MOSSO) algorithm to provide decision regarding conflict objectives and generate approximate Pareto front of non-dominated solutions. A comprehensive analysis of objective reduction approach is carried out with existing multi-objective methods on many-objective DTLZ and WFG test suite which highlight the superiority of proposed technique. Further, the performance of the proposed approach is evaluated on satellite images to detect cloudy region against various types of earth's surfaces. The performance of the proposed approach is compared against existing benchmark many-objective algorithm, NSGA-III in order to evaluate the potential of proposed method in clustering application. It is observed that obtained clustering results using reduced objective set of MOSSO algorithm provides almost equivalent accuracy with results obtained using NSGA-III with many-objective set.
\end{abstract}

Keywords Social spider optimization - remote sensing · cloud detection - objective reduction . many-objective optimization

Rachana Gupta, Satyasai Jagannath Nanda

Department of Electronics and Communication Engineering,

Malaviya National Institute of Technology,

Jaipur-302017, Rajasthan, India.

E-mail:2015rec9517@mnit.ac.in, sjnanda.ece@mnit.ac.in

\section{Introduction}

Satellite captures information of earth's surface for climatic study which includes change detection, surface identification, weather forecast and so on. These captured data becomes difficult to process for further analysis when they are distorted with cloudy information (Maktav, 2009, Jensen, 2009, Coakley Jr and Bretherton, 1982). This is a reason why cloud detection and hence cloud removal is an important satellite image pre-processing task to get the objective information more effectively (Berendes et al., 1999). This necessitates to design a clustering algorithm to extract cloud information from targeted input image. However, it is observed that conventional clustering algorithms stuck in local optimal solution (James and Li, 2015). To mitigate this issue, various studies have been done on optimization technique to obtain high accuracy in clustering problem. This has encouraged to formulate metaheuristic algorithm to acquire optimal solution and cluster the cloudy region over various types of earth's surface with minimum incorrect classification and least computational time complexity.

In this article, it is desirable to consider various objectives to satisfy better performance of cloud clustering problem with distinguish characteristic of earth's surfaces (Brockhoff and Zitzler, 2009; Saxena et al. 2012). The obtained solution-set provides different tradeoff between the desirable objectives. It means that obtained solution-set which is optimized in one objective compromises in other objectives. Therefore, a suitable solution is required to ensure satisfactory trade-off decision. This can be achieved by formulating the multiobjective optimization algorithms (Gupta et al., 2019).

One of the contributions introduced by Srinivas and Deb in multi-objective algorithm is non-dominated sort- 
ing genetic algorithm (NSGA-II) in which niche concept has been incorporated to deliver optimal solutions (Srinivas and Deb, 1994; Deb et al., 2002a; Nanda and Panda, 2014). During this time, rey Horn et al. (1994) developed niched Pareto based genetic algorithm, namely NPGA, using sharing operator. The encouraging results of NPGA is further extended as NPGA-II by incorporating fitness sharing scheme (Erickson et al., 2001). In the same duration, strength Pareto evolutionary algorithm (SPEA) has been introduced by adopting clustering technique in obtained optimal solutionset to reduce solutions without changing its characteristics (Zitzler and Thiele, 1999). Further, SPEA is enhanced to SPEA2 by including density estimation technique (Zitzler et al. 2001). In a different approach, the Pareto envelope-based selection algorithm (PESA) introduced hyper-grid concept in crowding method which is further incorporated in external archive (Corne et al. 2000). With similar approach, Pareto archived evolution strategy (PAES) was introduced to enhance the local search ability of the algorithm (Knowles and Corne, 2000). The computation with external archive is further introduced with multiple objectives particle swarm optimization (MOPSO) by combining the concept of archive controller with adaptive grid concept (Coello et al. 2004). In the same year, one more multi-objective algorithm was developed using decomposition technique named as MOEA/D which handles multi-objective problem as decomposed single-objective optimization problem (Zhang and Li, 2007). The recently proposed extended version of social spider algorithm has been developed, namely, multi-objective social spider clustering algorithm (MOSSO) to distinguish cloud in multispectral remote sensing images by optimizing centroids using similarity (SM) and variance (VAR) measures as objective functions (Gupta et al., 2019). However, till date there has not been seen any literature reports extending the applicability of SSO to solve many-objective optimization problems.Similarly, various studies have been made where single objective evolutionary methods are extended to multi-objective space to solve multiobjective problems (Babu and Gujarathi, 2007, Gupta et al., 2019).

Nevertheless, the modified multi-objective evolutionary algorithms (MOEAs) observed to provide least accuracy to handle many-objective optimization problems (MaOPs) with greater than 5-objective functions. Moreover, more examination is required on real-world problems to obtain effective outcomes. Over the few years, various contributions have been made to solve MaOPs in order to counter the limitation of existing MOEAs. These contributions have been made to enhance the convergence pressure and to maintain diver- sity among the solutions (Gupta and Nanda, 2019a). Therefore, studies on MOEAs have been extended to many-objective optimization algorithms like archive based MOEA/D (Cai et al., 2014), reference point based strategy in NSGA-II (NSGA-III) (Deb and Jain, 2013 Cheng et al. 2016) and angular based concept in NSGAII ( $\theta$-NSGA-III) (Xiang et al., 2016). It has been observed that modification in MOEAs fails to alleviate the visualizing difficulty in high dimensional Pareto front and making a decision for selecting optimal solutions (Deb and Jain, 2013; Liu et al., 2021, Chand and Wagner, 2015).

Thus, reduction in number of objectives is the most intuitive idea to overcome the difficulty while dealing with MaOPs (Ma et al., 2021). The motivation behind this idea is that, MaOPs consist $M$-objectives in practice in which a smallest $M^{\prime}\left(M^{\prime}<M\right)$ are conflict objectives. Such $M^{\prime}$ objectives are named as essential objective set whereas rest objectives are redundant objective set. The potential of the objective reduction technique is discussed in few studies (e.g., Brockhoff and Zitzler (2009); Saxena et al. (2012); López Jaimes et al. (2008)) based on two major aspects. First major aspect involves, if the size of redundant objective set is less than or equal to three then it can be solved efficiently by any MOEAs. In second aspect, the study shows ease in visualization of the Pareto front and decision making process even though the reduced objectives are more than three in obtained result.

Taking this into consideration, present article focuses around the objective reduction technique associated with feature selection method. Feature selection method has been largely utilized in various machinelearning techniques. The basic idea of feature selection in data analysis found useful to achieve objective reduction to solve MaOPs which has inspired with contributions such as Saxena et al. (2012); López Jaimes et al. (2008); Deb and Saxena (2006) to this study. However, direct usage of standard feature selection method to solve MaOPs provides least accuracy. This is due to the fact that algorithm needs to be taken care of conflict behavior among the objectives (López Jaimes et al., 2008). Recently, evolutionary computation approach (Xue et al., 2015) has grabbed wide attention in feature selection method because of its global search ability in multi-modal search space. These contributions of objective reduction technique have been reported based on correlation and dominance structure. Dominance based structure aims to preserve dominance among the objectives whereas correlation based structure preserves the most conflict objectives and eliminates the objectives which are non-conflict with other objectives. However, conventional studies are evalu- 
ated without considering desired error tolerance and number of objectives (Yuan et al. 2017).

Feature selection and extraction concepts have been used to reduce the objective-set in many-objective optimization algorithm (Ding et al., 2021). The investigation has been done by adding or removing the objectives on the Pareto dominance relation (Brockhoff and Zitzler, 2009). Saxena et al. (2012) used principle component analysis and maximum variance unfolding based method for objective reduction. Further, few more contributions have been observed in terms of correlation based approach that give minimum number of objectives with minimum possible error value (López Jaimes et al., 2008: Singh et al., 2011a). For example, Pareto corner search evolutionary algorithm (PCSEA) has been focused on objective reduction concept using dominance and correlation based approach (Singh et al., 2011b). Wang et. al. proposed a new concept of non-linear correlation entropy based approach into Pareto and indicator based MOEAs (Wang and Yao, 2016). A concept of aggregation of tree has been introduced as dimensionality reduction technique for the visualization of the results in high-dimensional objective space (de Freitas et al., 2015). Brockhoff et. al. introduced objective reduction with hypervolume based evolutionary algorithms to reduce the computational time complexity of the algorithm (Brockhoff and Zitzler, 2007).

Literature reveals that use of correlation-based approach cannot ensure the preservation of dominance relation and also fails to indicate the reason behind the downside of the algorithm (Brockhoff and Zitzler, 2009: Singh et al. 2011b. Therefore, present work discusses MOEA in objective reduction technique using correlation structure with following major contributions.

- A many-objective reduction technique using multiobjective social spider optimization (MOSSO) is introduced by incorporating correlation based errors in the objective space.

- The performance of MOSSO reduction technique is validated on fourteen many-objective test problems by comparing it with existing many-objective evolutionary algorithms.

- Proposed method is further employed to solve cloud clustering problem in multi-spectral satellite images in order to evaluate the accuracy of clustered result with reduced objective set over original objective set.

The remainder of present article is arranged as follows. Section II presents the proposed multi-objective evolutionary approach in detail. Section III conducts a critical analysis on benchmark test problems in or- der to show the general strengths and limitations of the proposed approach. Section IV presents the benefits of proposed multi-objective reduction technique in cloud detection application. Lastly, the concluding remarks are given in Section V.

\section{Proposed Objective Reduction Method}

This section describes the objective reduction technique with MOSSO method to solve many-objective problem. The idea to remedy objective reduction problem is proposed by utilizing high search potential of MOSSO method to obtain conflict objectives. This is the important motivation of promoting appication of MOSSO approach in developing objective reduction algorithm.

\subsection{Multi- and Many-objective Optimization Problem}

A general multi-objective problem is formulated with $M$ objective functions, $f_{j}(x): \aleph \rightarrow \xi_{j}, j \in\{1,2, \ldots, M\}$ in $\aleph_{\text {dim }}$ decision space, $\operatorname{dim} \in\{1,2, \ldots, D\}$, where $\xi_{j} \subseteq \mathbb{R}$ is a objective space and $D$ is the dimension of decision space. A general minimization problem for $N$ population is defined as,

$$
\begin{array}{r}
\text { Minimize } \mathbf{Y}_{N}=\left[f_{j}(\mathbf{X}), j=1,2, \ldots, M\right] \\
\text { Subject to : } \\
G_{k}(\mathbf{X}) \leq 0, k=1,2, \ldots, K \\
H_{l}(\mathbf{X})=0, l=1,2, \ldots, L
\end{array}
$$

where, $\mathbf{Y}=\left[f_{1}(\mathbf{X}) f_{2}(\mathbf{X}) \ldots f_{M}(\mathbf{X})\right]$ is a objective vector, $G_{k}(\mathbf{X})$ and $H_{l}(\mathbf{X})$ is the $k^{\text {th }}$ and $l^{\text {th }}$ inequality and equality constraint, respectively. Multi-objective problem is then utilized to get the optimal decision variable $\left(\mathbf{X}^{*}\right)$. The objective vector, $\mathbf{Y}$ in less than four-dimensional objective space is said to be the solution of multi-objective problems or else it becomes the solution of MaOPs.

\subsection{Multi-objective social spider optimization (MOSSO)}

The size of spider population $\left(S_{i}\right)$ is assumed to be $N$. The entire colony is divided into female ( female $_{i}$ ) and male $\left(\right.$ male $\left._{i}\right)$ spider population. The spiders crawl on the web and produce vibrations while updating their positions. Here, the vibration intensity act as a information transmission medium to share information of one spider with other spiders present in the colony. The initial step is to set the vibration intensity $(V)$ as 0 produced by each spider, $V_{i}=0, i \in\{1,2,3, \ldots, N\}$. Spiders update their position by distinguishing vibrations 
from individual in a colony and sensing its intensity on web (Gupta and Nanda, 2019a). Algorithm 1 describes the entire mathematical model of MOSSO algorithm.

The initial stage of MOSSO approach is to compute vibration intensity of each spider which is highly dependent on each individual weight. The weight of the spiders is decided by the fitness value of each individual, such that $\mathbf{W}_{i}, \mathrm{i} \in\{1,2, \ldots, N\}$, as equated in Eq. 2. The spider with minimum weight is considered as fittest individual of entire colony. Further, vibration of each individual is computed according to its computed weight, modeled in Eq. 3 .

$\mathbf{W}_{N}=\left[f_{j}\left(\mathbf{S}_{N}\right), j=1,2\right]$

$V_{i, N}=\mathbf{W}_{N} \cdot e^{-d_{i, N}^{2}}$

where, $\mathbf{W}_{N}$ demonstrates the weight of $S_{N}$ spider and $d_{i, N}$ gives the distance of $S_{N}$ from $S_{i}$ spider. The vibration intensity is further utilized to compute the position of each individual using female and male cooperative operator.

The entire spider population is then divided into $60 \%$ and $40 \%$ as female and male population, respectively. The female cooperative operator updates the position of female spiders based on the location of nearest spider $\left(S_{C}\right)$ with minimum weight and on the location of fittest spider of the colony $\left(S_{B}\right)$. The female cooperative operator is modeled in Eq. 4.5, represents the position update rule of female spider based on its attraction and repulsion movement, respectively, by using probability $\mathbb{P}$ parameter as $20 \%$.

$$
\begin{aligned}
\text { female }_{i}^{t+1}= & \text { female }_{i}^{t}+\gamma V_{C, i}\left(S_{C}-\text { female }_{i}^{t}\right)+ \\
& \vartheta V_{B, i}\left(S_{B}-\text { femal }_{i}^{t}\right)+\delta\left(\text { rand }-\frac{1}{2}\right) \\
\text { female }_{i}^{t+1}= & \text { female }_{i}^{t}-\gamma V_{C, i}\left(S_{C}-\text { female }_{i}^{t}\right)- \\
& \vartheta V_{B, i}\left(S_{B}-\text { female }_{i}^{t}\right)+\delta\left(\text { rand }-\frac{1}{2}\right)
\end{aligned}
$$

where, $t$ shows the generation, $\gamma$ and $\vartheta$ are taken as $40 \%$ of total probability (providing similar probability to global and local search) and $\delta$ is considered as remaining probability with $20 \%$.

Male cooperative operator is model in Eq. 6. which demonstrates that position of male spiders get updated based on the position of nearest fittest female spider $\left(S_{F}\right)$ and the probability of its random walk. This help to maintain diversity between the obtained solutions with respect to female and male spiders.

$$
\text { male }_{i}^{t+1}=\text { male }_{i}^{t}+\gamma V_{F, i}\left(S_{F}-\text { male }_{i}^{t}\right)+\delta\left(\operatorname{rand}-\frac{1}{2}\right)
$$

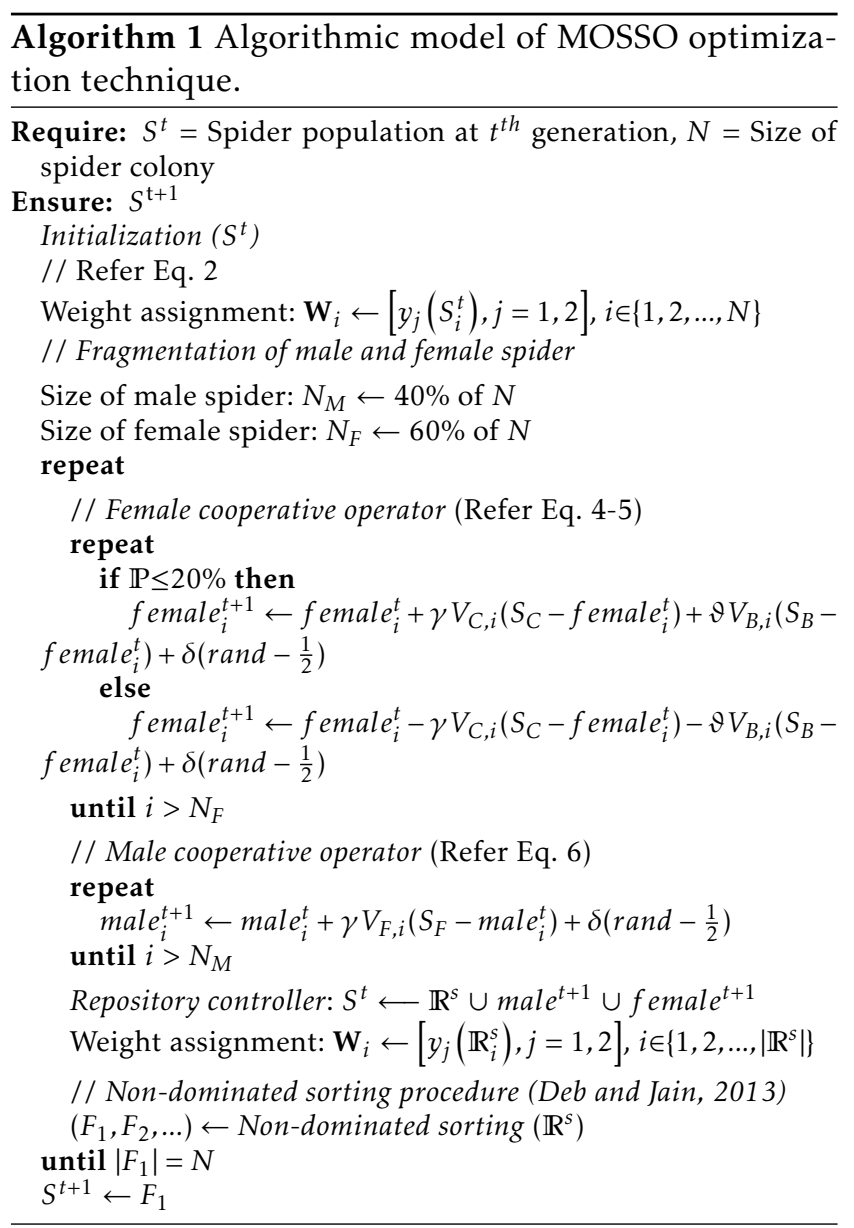

The decision of updated position of each spider is stored in repository controller $\left(\mathbb{R}^{S}\right)$ where repeated solutions are removed to maintain diversity among solutions and reduce the computation time complexity. Further, the solution of $\mathbb{R}^{s}$ is sorted into distinguish fronts with non-dominated solution-set by using non-dominated sorting method to select optimal $N$ members $\left(F_{1}, F_{2}\right.$, ...). This entire process is continued until all the $N$ non-dominated solutions belong to the member of optimal first front $\left(F_{1}\right)$ (Gupta et al., 2019).

\subsection{Concepts of Objective Reduction}

The original objective set is represented as $\mathbf{Y}=\left\{f_{1}, f_{2}, \ldots, f_{M}\right\}$ and refers as true Pareto front of MaOP. For the convenience, $\mathbf{Y}_{R}$ is used to demonstrate the sub-vector with non-empty objective set. One of the fundamental criteria is to generate essential objective-set in objective reduction approach (Saxena et al., 2012) to solve MaOP which is described with definition as,

Definition 1: An objective subset $\mathbf{Y}_{R} \subset \mathbf{Y}$ is a redundant objective subset whose ejection does not influence the Pareto front of targeted problem. This redundant ob- 


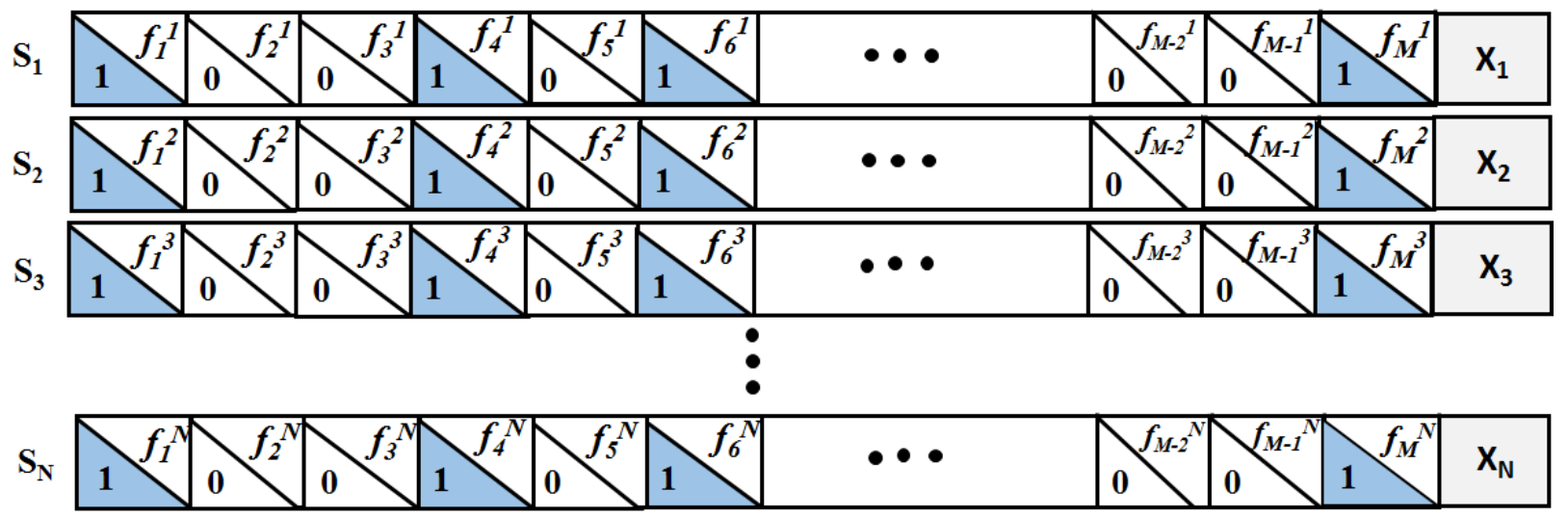

Fig. 1: Binary string initialization of spider population

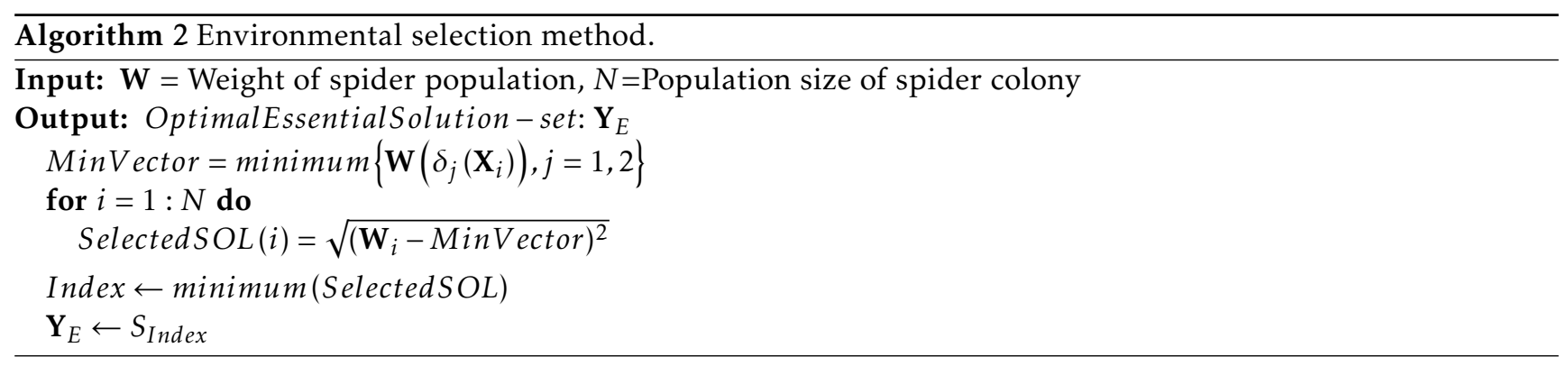

jective set is generally non-conflicting in nature or the objectives are correlated with other objectives.

Definition 2: An objective subset $\left\{\mathbf{Y}_{E} /\left|\mathbf{Y}_{E}\right|=M^{\prime}\right\}$ is an essential objective subset whose objectives are conflict in nature and generate similar Pareto front as that of generated by original objective set $\mathbf{Y}$.

The non-conflicting objectives is an another important concept in the objective reduction technique. If $f_{i}$ objective function has a non-conflicting behavior with $f_{j}$, then one of the objectives is removed from the pool of objectives. The degree of conflicting behavior is estimated using correlation concept. The positive correlation between the objectives shows the non-conflict behavior while negative value demonstrates that the objectives are more to be conflicting.

\subsection{Proposed methodology}

This section discusses proposed methodology of objective reduction algorithm using MOSSO approach.

\subsubsection{Initialization of spider population}

The initial iterative stage of MOSSO objective reduction method is the initialization of position vector of entire spider colony. The position of each spider population is depicted in binary form as well as decision variable vector of test problem. The binary string in initialization stage of each individual depicts its decision of selecting the essential objective set. This is mathematically formulated as,

$$
\left[\begin{array}{c}
S_{1} \\
S_{2} \\
S_{3} \\
\vdots \\
\vdots \\
S_{N}
\end{array}\right]=\left[\begin{array}{ccccccc}
1 & 0 & 1 & \ldots & \ldots & 0 & \mathbf{X}_{1} \\
0 & 0 & 1 & \ldots & \ldots & 1 & \mathbf{X}_{2} \\
1 & 1 & 1 & \ldots & \ldots & 0 & \mathbf{X}_{3} \\
\vdots & \vdots & \vdots & \vdots & \vdots & \vdots \\
\vdots & \vdots & \vdots & \vdots & \vdots & \vdots \\
1 & 1 & 1 & \ldots & \ldots & 0 & \mathbf{X}_{N}
\end{array}\right]_{N \times(M+D)}
$$

Fig. 1 shows the representation of initialization operator for $N$ spider population. $f_{1}, f_{2}, \ldots, f_{M}$ of $M$ dimensional objective-set is represented in upper triangle whereas decision of essential objectives is shown in binary form in lower triangle of the box. The lower triangle with gray in background demonstrates the decision with ' 1 ' which represents of selecting particular objective as a member of essential objective set. However, remaining objectives are made ' 0 ' in lower triangle of white background box.

\subsubsection{Objective functions as weight of each spider}

Each individual spider is having its weight corresponds to its fitness value. The spider with minimum weight 


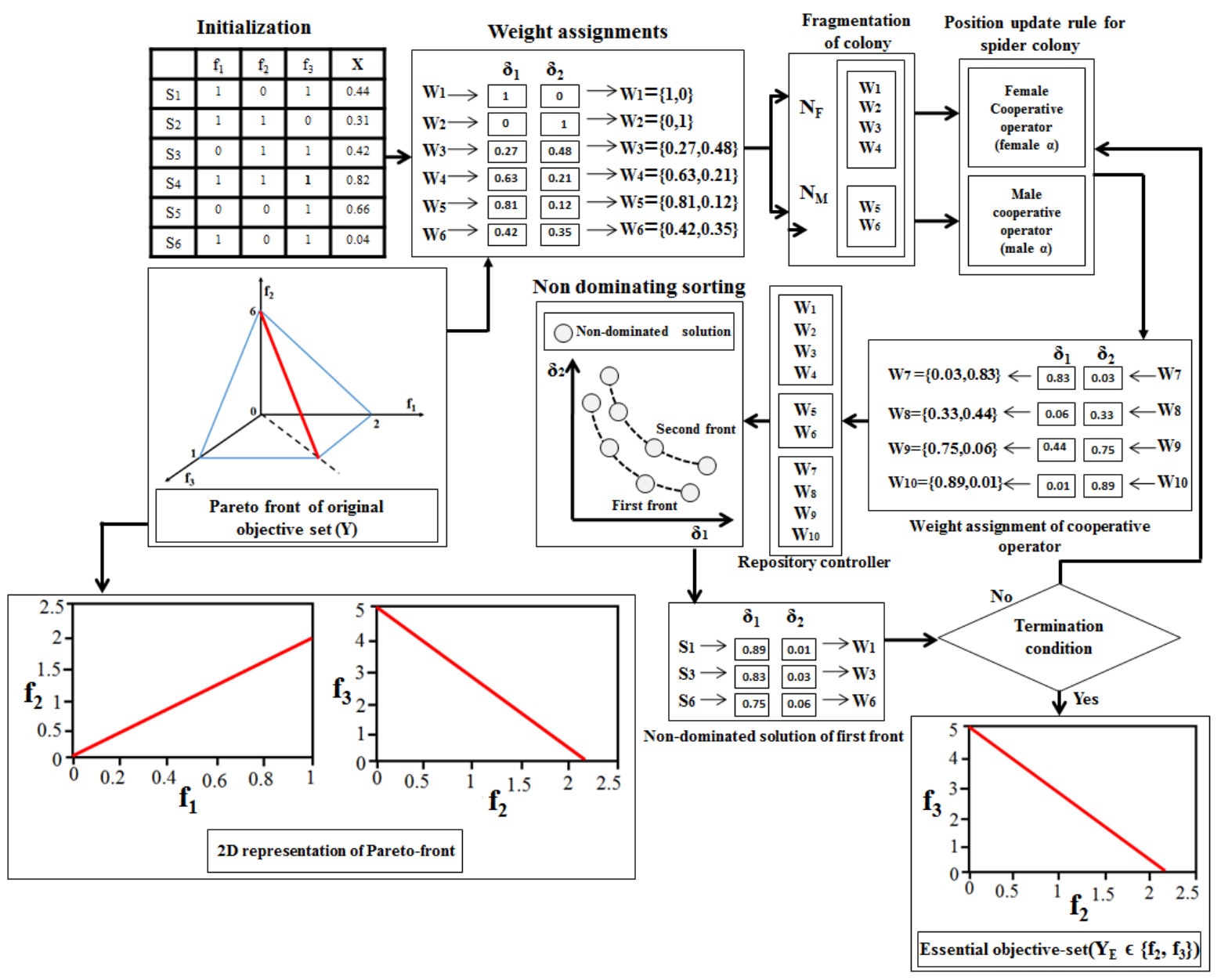

Fig. 2: Flow of MOSSO objective reduction approach to solve many-objective problems

indicates the fittest individual in the entire colony. The weightof $i^{\text {th }}$ spider, $\mathbf{W}_{i}, \mathrm{i} \in\{1,2, \ldots, N\}$ can be formulated as in Eq. 8 .

$\mathbf{W}_{i}=\left[\delta_{j}\left(\mathbf{S}_{i}\right)\right], j=1,2$.

where, $\delta_{j}$ shows the correlation error among the objectives of the input sample set. The objective reduction technique tries to reduce the objectives such that nonconflicting objectives are removed from the original objective set. The following are two important mathematical functions corresponding to correlation based approach which has been identified to handle objective reduction problem.

1. Pearson correlation Error $\left(\delta_{1}\right)$ reflects the measure of computing the correlation among each objective vector $(\mathbf{Y})$ of each individual. The minimum correlation among the objective vectors indicates more conflict behavior of the objectives, such that

$$
\delta_{1}=\min \left\{\operatorname{var}\left(\frac{\operatorname{cov}\left(f_{1}^{N}, f_{2}^{N}, \ldots, f_{M^{\prime}}^{N}\right)}{\operatorname{std}\left(f_{1}^{N}, f_{2}^{N}, \ldots, f_{M^{\prime}}^{N}\right)}\right)\right\}
$$

2. Inter-distance correlation Error $\left(\delta_{2}\right)$ demonstrates the measure of the task of grouping the objective set which are more conflict with each other. This shows the degree of compactness among objectiveset with non-conflict in nature. Therefore, $\delta_{2}$ is expected to be minimized as an objective and hence mathematically formulated by taking ratio of summation of distance measured with each chosen objective vector, such that $f_{i}^{N} \in M^{\prime}$.

$$
\delta_{2}=\min \left\{\frac{1}{\sum_{p=1}^{k} \sum_{q=p+1}^{M^{\prime}}\left(f_{p}^{N}-f_{q}^{N}\right)^{2}}\right\}
$$

where, $\mathrm{k}$ is $\left(\frac{M^{\prime} !}{\left(M^{\prime}-2\right) ! 2 !}\right), M^{\prime}$ is the size of decision of selecting the objectives by individual member and $f_{i}^{N}$ is 
a $i^{\text {th }}$ objective value of $N^{\text {th }}$ population in the original objective-set.

Thereafter, decision of updated position of each spider is computed using male and female cooperative operator with Eq. 5 6 6 which is further stored in repository controller $\left(\mathbb{R}^{s}\right)$ where repeated solutions are removed so that diversity can be maintained among solutions. Further, the solution of $\mathbb{R}^{s}$ is sorted into different non-dominated fronts $\left(F_{1}, F_{2}, \ldots\right)$ to select optimal solutions. This entire process is continued until all the non-dominated solutions belong to the member of first front $\left(F_{1}\right)$.

\subsubsection{Environmental selection method to pick optimal decision}

Environmental selection method is to be followed after going through the steps of position update rule of each spider discussed in MOSSO algorithm (Gupta et al., 2019). The core functionality of environmental selection method is to produce optimal solution from nondominated Pareto solution set from the distribution of non-dominated solutions of first front in the objective space, as discussed in Algorithm 2 Each solution corresponds to the decision of selecting the objective function of each spider. The main aim of Environmental selection method is to choose fittest solution with minimum value in $\delta_{1}$ and $\delta_{2}$ objectives. Therefore, non-dominated optimal solution having minimum values in both the objective functions is chosen from first front of non-dominated solution-set. The obtained optimal solution corresponds to the decision of essential objective functions $\left(\mathbf{Y}_{E}\right)$ and eliminates the redundant objective functions.

The algorithm model of proposed multi-objective objective reduction approach is summarized in Fig. 2. It is observed that MOSSO algorithm uses correlation structure from the Pareto front of original objective set which generates the non-conflicting behavior of $f_{1}$ and $f_{2}$ objective functions and demonstrates the conflicting behavior of either of them with $f_{3}$ objective function. This helps to identify essential objective set which indeed not a good Pareto front approximation (inaccurate convergence towards true Pareto front) but it is a good Pareto front representation. This entire process is continued until the termination condition is met, otherwise male and female spider position updation rule is repeated.

\section{Validation on Many-Objective Test Functions}

The performance evaluation of the proposed approach is carried on inverse generational distance (IGD), spac- ing (SP), hypervolume difference (HVD) and delta $(\Delta)$ metrics to permit its quantitative assessment with different many-objective test problems. The existing benchmark multi-objective optimization methods (i.e. MOPSO and SPEA2) are adopted for comparison and it is observed that performance of the proposed approach is better in most of the cases. This conclusion is validated by the analysis and comparison over DTLZ and WFG many-objective test suite.

\subsection{Test Problems}

The many-objective test problems are examined to asses MOSSO approach as objective reduction technique over existing multi-objective algorithms. Different fourteen unconstrained test problems with five DTLZ (Deb et al. 2002b) and nine WFG (Tanigaki et al., 2016) are used in this manuscript. All the test problems are evaluated with 10 and 12 objective functions such that $f_{i} \in[0,1]$. The DTLZ test problem is used with three decision variables whereas WFG is used with $(M-1)$ decision variables.

\subsection{Experimental settings}

The independent run of all the algorithms is taken as 20 with maximum generation of 50 for each considered test problems. The repository length of MOPSO is taken equivalent to population size. The adaptive grid concept utilized in MOPSO is utilized with $30 \mathrm{di}-$ vision and mutation rate of 0.5 (Coello et al. 2004). The external archive of SPEA2 is chosen as one fourth of considered initial population size as per advised by its developers to meet the required selection pressure on optimal solution set. The initial population size of each compared algorithm is chosen as 30 Gupta et al. 2019).

\subsection{Discussion of the results}

The main aim of this article is to solve many-objective problem with multi-objective algorithm. Therefore, comparative analysis of the proposed approach is evaluated against two conventional methods of multi-objective algorithms that are MOPSO and SPEA2 to solve manyobjective DTLZ and WFG test problems. The compared methods are evaluated on MATLAB R2015b with Intel 2.30 GHz i5 microprocessor and 4.0 GB RAM. 
Table 1: $\delta$-error computation using MOSSO approach for sample set of DTLZ test suite.

\begin{tabular}{ccccc}
\hline Test function & $M$ & $\delta_{1}$ & $\delta_{2}$ & Objective set \\
\hline \multirow{2}{*}{ DTLZ1 } & 10 & $7.49 \mathrm{E}+01$ & $1.02 \mathrm{E}-02$ & $\{\mathrm{f} 1, \mathrm{f} 2, \mathrm{f} 5, \mathrm{f} 7, \mathrm{f} 9\}$ \\
& 12 & $2.26 \mathrm{E}+01$ & $6.58 \mathrm{E}-02$ & $\{\mathrm{f} 1, \mathrm{f} 2, \mathrm{f} 5, \mathrm{f} 9, \mathrm{f} 12\}$ \\
DTLZ2 & 10 & $9.26 \mathrm{E}+00$ & $8.41 \mathrm{E}-01$ & $\{\mathrm{f} 1, \mathrm{f} 3, \mathrm{f} 4\}$ \\
& 12 & $4.81 \mathrm{E}+00$ & $1.67 \mathrm{E}-01$ & $\{\mathrm{f} 11, \mathrm{f} 12\}$ \\
DTLZ3 & 10 & $4.90 \mathrm{E}+01$ & $2.62 \mathrm{E}-01$ & $\{\mathrm{f} 1, \mathrm{f} 5, \mathrm{f} 6\}$ \\
& 12 & $5.61 \mathrm{E}+01$ & $6.40 \mathrm{E}-03$ & $\{\mathrm{f} 2, \mathrm{f} 3, \mathrm{f} 6, \mathrm{f} 7\}$ \\
DTLZ4 & 10 & $1.69 \mathrm{E}+00$ & $1.31 \mathrm{E}-02$ & $\{\mathrm{f} 1, \mathrm{f} 2, \mathrm{f} 3, \mathrm{f} 4, \mathrm{f} 5, \mathrm{f} 6, \mathrm{f} 7, \mathrm{f} 10\}$ \\
& 12 & $6.11 \mathrm{E}-01$ & $5.86 \mathrm{E}-02$ & $\{\mathrm{f} 2, \mathrm{f} 3, \mathrm{f} 5, \mathrm{f} 12\}$ \\
DTLZ5 & 10 & $4.68 \mathrm{E}+01$ & $1.94 \mathrm{E}-01$ & $\{\mathrm{f} 4, \mathrm{f} 5, \mathrm{f} 6, \mathrm{f} 7\}$ \\
& 12 & $3.21 \mathrm{E}+00$ & $2.14 \mathrm{E}-01$ & $\{\mathrm{f} 11, \mathrm{f} 12\}$ \\
DTLZ6 & 10 & $6.69 \mathrm{E}+01$ & $1.33 \mathrm{E}-01$ & $\{\mathrm{f} 6, \mathrm{f} 9, \mathrm{f} 10\}$ \\
& 12 & $2.06 \mathrm{E}+01$ & $7.49 \mathrm{E}+00$ & $\{\mathrm{f} 1, \mathrm{f} 3, \mathrm{f} 6\}$ \\
\hline
\end{tabular}

Table 2: Mean and standard deviation of IGD performance metric on DTLZ problem for 20 independent runs. Best results are shown in bold font style.

\begin{tabular}{|c|c|c|c|c|c|c|}
\hline \multirow{3}{*}{$\begin{array}{c}\text { Test } \\
\text { Problem }\end{array}$} & \multicolumn{6}{|c|}{ IGD } \\
\hline & \multicolumn{2}{|c|}{ MOSSO } & \multicolumn{2}{|c|}{ MOPSO } & \multicolumn{2}{|c|}{ SPEA2 } \\
\hline & Mean & Std. Dev. & Mean & Std. Dev. & Mean & Std. Dev. \\
\hline DTLZ1 & $1.80 \mathrm{E}-03$ & $2.22 \mathrm{E}-19$ & $1.91 \mathrm{E}-03$ & $3.45 \mathrm{E}-04$ & $2.72 \mathrm{E}-03$ & $1.44 \mathrm{E}-03$ \\
\hline DTLZ2 & $8.09 \mathrm{E}-03$ & $3.83 \mathrm{E}-04$ & 7.93E-03 & $1.83 E-18$ & $7.50 \mathrm{E}-03$ & $2.66 \mathrm{E}-03$ \\
\hline DTLZ3 & $9.49 \mathrm{E}-03$ & $7.95 \mathrm{E}-03$ & $2.08 \mathrm{E}-02$ & $1.04 \mathrm{E}-05$ & $1.31 \mathrm{E}-02$ & $1.83 \mathrm{E}-18$ \\
\hline DTLZ4 & $4.65 \mathrm{E}-03$ & $1.78 \mathrm{E}-18$ & $4.69 \mathrm{E}-03$ & $1.12 \mathrm{E}-04$ & $8.21 \mathrm{E}-03$ & $5.22 \mathrm{E}-03$ \\
\hline DTLZ5 & $2.22 \mathrm{E}-02$ & $7.12 \mathrm{E}-18$ & $2.56 \mathrm{E}-02$ & $1.08 \mathrm{E}-02$ & $6.88 \mathrm{E}-02$ & 7.09E-02 \\
\hline DTLZ6 & $7.74 \mathrm{E}-03$ & $2.58 \mathrm{E}-06$ & $1.19 \mathrm{E}-02$ & $0.00 \mathrm{E}+00$ & $7.97 \mathrm{E}-03$ & $4.00 \mathrm{E}-03$ \\
\hline
\end{tabular}

Table 3: Mean and standard deviation of SP performance metric on DTLZ problem for 20 independent runs. Best results are shown in bold font style.

\begin{tabular}{|c|c|c|c|c|c|c|}
\hline \multirow{3}{*}{$\begin{array}{c}\text { Test } \\
\text { Problem }\end{array}$} & \multicolumn{6}{|c|}{ SP } \\
\hline & \multicolumn{2}{|c|}{ MOSSO } & \multicolumn{2}{|c|}{ MOPSO } & \multicolumn{2}{|c|}{ SPEA2 } \\
\hline & Mean & Std. Dev. & Mean & Std. Dev. & Mean & Std. Dev. \\
\hline DTLZ1 & $7.82 \mathrm{E}-02$ & $4.27 E-17$ & $7.83 \mathrm{E}-02$ & $3.84 \mathrm{E}-04$ & 7.85E-02 & $5.12 \mathrm{E}-04$ \\
\hline DTLZ2 & $1.10 \mathrm{E}-02$ & $3.58 \mathrm{E}-04$ & $9.96 \mathrm{E}-03$ & $1.83 E-18$ & $1.04 \mathrm{E}-02$ & $4.26 \mathrm{E}-03$ \\
\hline DTLZ3 & $3.10 \mathrm{E}-01$ & $8.84 \mathrm{E}-02$ & $4.00 \mathrm{E}-03$ & 8.01E-04 & $6.85 \mathrm{E}-02$ & $0.00 \mathrm{E}+00$ \\
\hline DTLZ4 & $7.50 \mathrm{E}-03$ & $4.45 \mathrm{E}-18$ & $8.20 \mathrm{E}-03$ & $2.21 \mathrm{E}-03$ & $1.81 \mathrm{E}-02$ & $8.05 E-03$ \\
\hline DTLZ5 & 7.99E-03 & $1.78 \mathrm{E}-18$ & $8.78 \mathrm{E}-03$ & $2.51 \mathrm{E}-03$ & $1.04 \mathrm{E}-02$ & $5.37 \mathrm{E}-03$ \\
\hline DTLZ6 & 7.71E-04 & $2.28 \mathrm{E}-19$ & $7.71 \mathrm{E}-04$ & $1.25 \mathrm{E}-19$ & $3.09 \mathrm{E}-04$ & $3.98 \mathrm{E}-04$ \\
\hline
\end{tabular}

\subsubsection{Results on DTLZ test suite}

The proposed objective reduction technique using multiobjective approach returns a number of reduced nondominated objective subset with corresponding objective reduction errors $\left(\delta_{1}\right.$ and $\left.\delta_{2}\right)$. Table 1 shows the result of $\delta$-error for sample set of 10 -objective and 12objective functions. It is observed that $\delta_{1}$ value de- creases with increased size of an objective set whereas $\delta_{2}$ leads to larger error with objectives. Therefore, a tradeoff among the errors is required towards the optimal decision.

MOSSO is a multi-objective optimization algorithm which can solve the test problems with maximum 3 objective functions $(\mathrm{M}<4)$. The present work focuses on solving many-objective function with $\mathrm{M}>3$ using 
multi-objective reduction algorithm using MOSSO. There-3.4 Results on WFG test suite

fore, the comparison is carried out using the performance matrix such as IGD, SP, HVD and Delta with proposed MOSSO objective reduction algorithm with multi-objective MOPSO and SPEA2 optimization algorithms.

Fig. 3 with 10-objective and Fig. 4 with 12-objective sample-set demonstrate the parallel plots of reduced objectives. It is observed that, the proposed algorithm reduces number of objectives with different test problems over large number of objectives in the sample set. The conflict behavior of reduced objective set reveals the better performance of proposed approach on DTLZ test suite with increased number of objectives. The corresponding Pareto front to show the evaluation performance is shown in Fig. 5 for 10 and 12 objectives, respectively.

The potential of proposed objective reduction approach in terms of IGD metric is shown in Table 2 . The better performance of MOSSO approach is reported over compared algorithms for all the test problems except in DTLZ2. However, large value of IGD indicates that SPEA2 and MOPSO found difficulty in meeting the convergence pressure. Further, Table 2 shows the low value of standard deviation using proposed approach in most the cases which indicates IGD value tend to be close to the mean value in each run. This clearly reveals the better performance of MOSSO approach in objective reduction technique in case of converging the obtained solution set.

The slightly large value of SP metric, shown in Table 3 indicates lower performance of the proposed approach on DTLZ2, DTLZ3 and DTLZ6 problems. Among tested many-objective problems, the large value of MOPSO found difficulty in maintaining a uniform distribution except for DTLZ2 and DTLZ3 whereas SPEA2 seems to show least encouraging performance in terms of SP value.

The roughly consistent value of HVD metric presented in Table 4 is observed with the IGD value in Table 2. Clearly, the proposed method is observed to be a promising algorithm in majority of the test cases, however it is outperformed by MOPSO on DTLZ3. The Delta metric of three compared method is given in Table 5 It is observed that the proposed MOSSO objective reduction technique outperforms on majority of DTLZ problems. This validates the performance of the proposed approach to solve MaOPs in terms of convergence and diversity among the non-dominated solution set.

Table 6 reports the potential performance of MOSSO algorithm in terms of IGD over compared algorithms for most of the WFG test problems. However, MOSSO seems struggling for maintaining convergence for WFG4 with 12-objective sample set and WFG6 with 10-objective sample set. SPEA2 and MOPSO found difficulty in meeting the convergence pressure as reported by larger IGD value except for WFG6 and WFG4 test problems, respectively.

The larger value of SP metric, given in Table 7 demonstrates distribution characteristics of obtained solution set. It is reported that the proposed MOSSO objective reduction technique gives lower performance on WFG3, WFG5 and WFG9. Among tested problems, MOPSO seems difficult to meet uniform distribution of obtained solutions as can be observed with large SP value in most of the test problems except for WFG4 and WFG9 with 12 and 10 objective sample set, respectively. Whereas SPEA 2 shows encouraging outcome for WFG3 and WFG5 in all the cases. Further, Table 2 shows the low value of standard deviation using the proposed approach in most the cases which indicates SP value tend to be close to the mean value in each run. This demonstrates the robust performance of the algorithm in terms of diversity among the solutions. Table 8 presents roughly consistent $\Delta$ performance metric for WFG test problem.

Fig. 6 with 10-objective and Fig.7 7 with 12-objective sample-set demonstrate the parallel plots of reduced objectives using proposed MOSSO approach with WFG test problems. The conflict behavior of reduced objective set reveals the better performance of MOSSO on WFG test suite with increased number of objectives. The corresponding Pareto front to show the evaluation performance is shown in Fig. 8 for 10- and 12-objective sample set, respectively.

Clearly, the proposed MOSSO objective reduction is observed to be more promising algorithm than compared methods in majority of the cases and performance metrics. However, it is outperformed by compared algorithms on DTLZ2, WFG3 and WFG5. This validates the performance of the proposed approach to solve $\mathrm{MaOPs}$ in terms of convergence and diversity among the non-dominated solution set.

\section{Cloud Detection in Satellite Images}

This section discusses the performance evaluation of proposed reduction technique to handle many-objective clustering problem in satellite images. The obtained result using reduced objective set with the proposed 

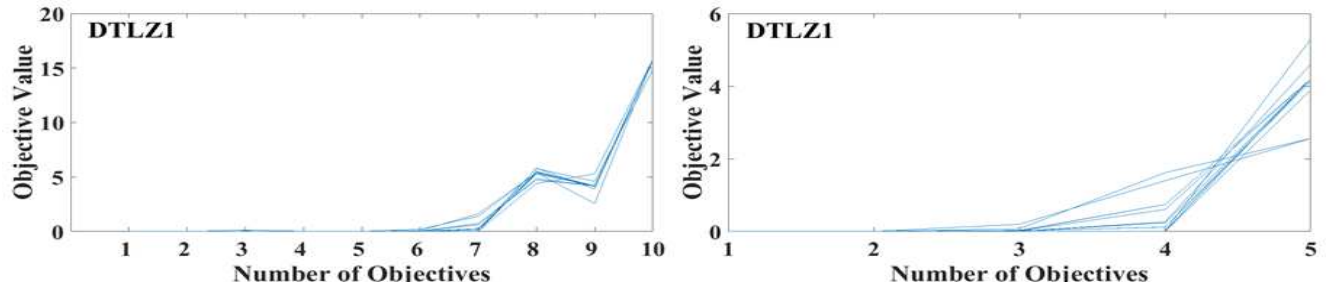

(a)

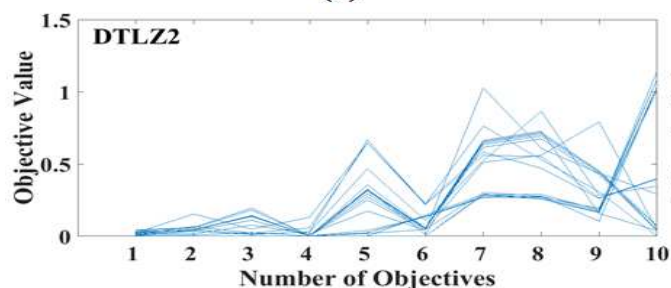

(g)

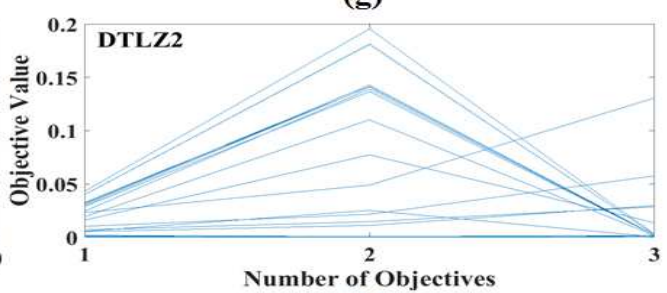

(b)
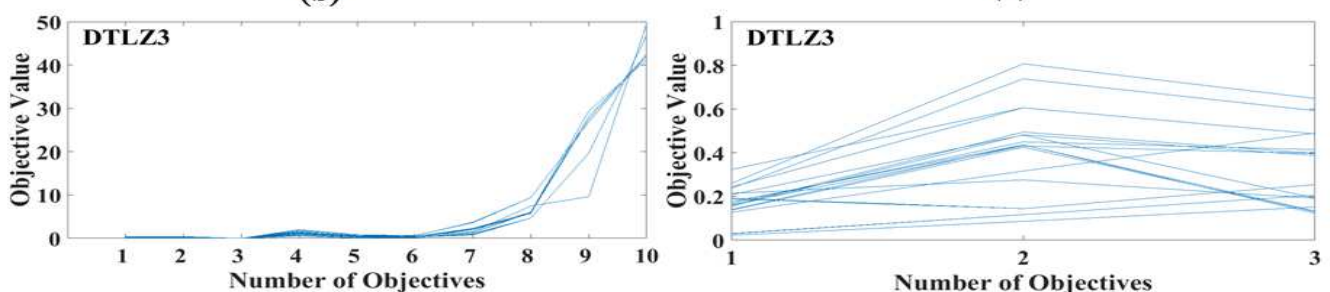

(c)

(i)
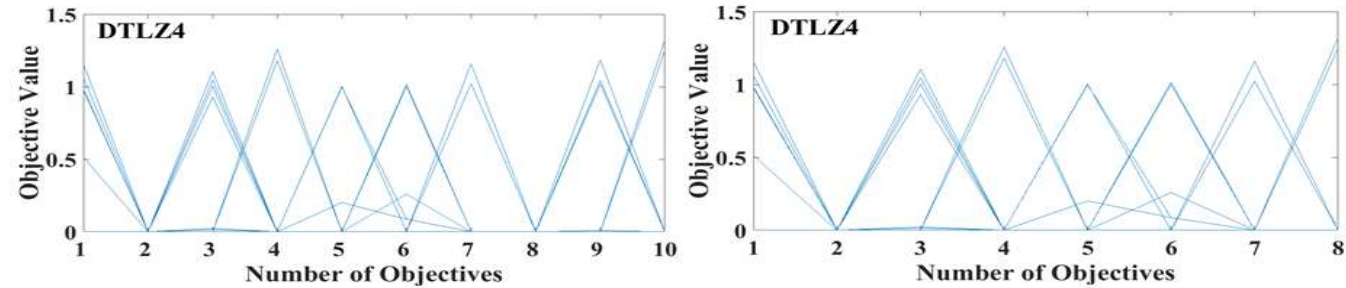

(d)

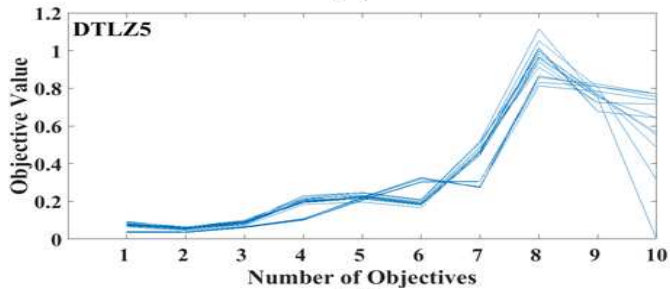

(j)

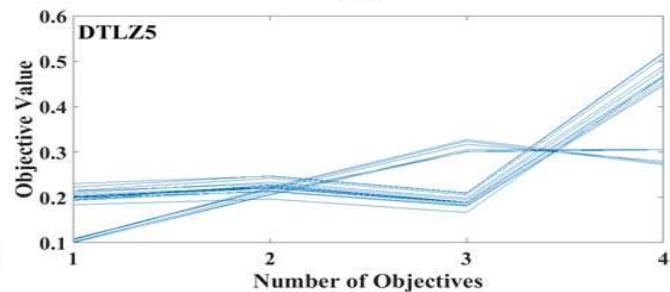

(e)

(k)

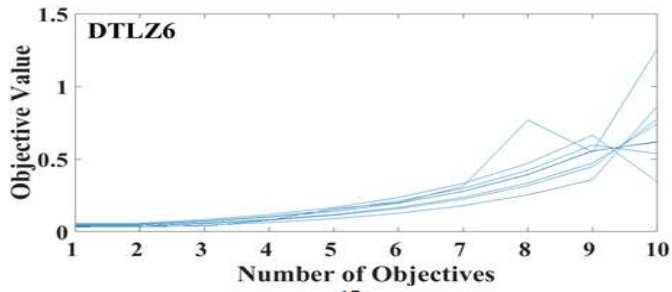

(f)

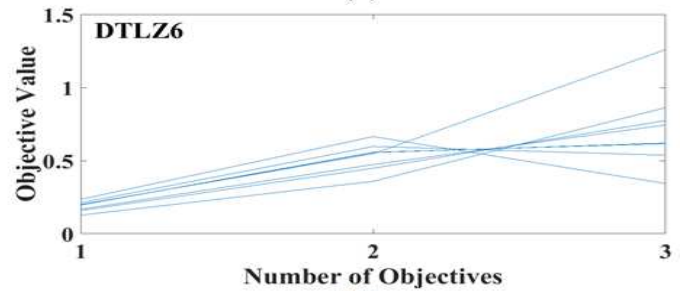

(I)

Fig. 3: Graphical result for DTLZ test suite with 10 objectives from MOSSO: (a-f) Parallel plot of original objective-set, (g-l) Parallel plot of essential objective-set. 

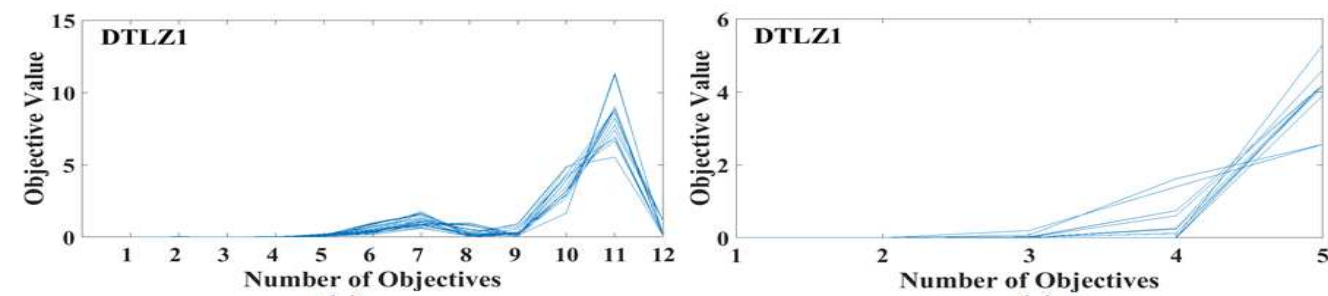

(a)

(g)
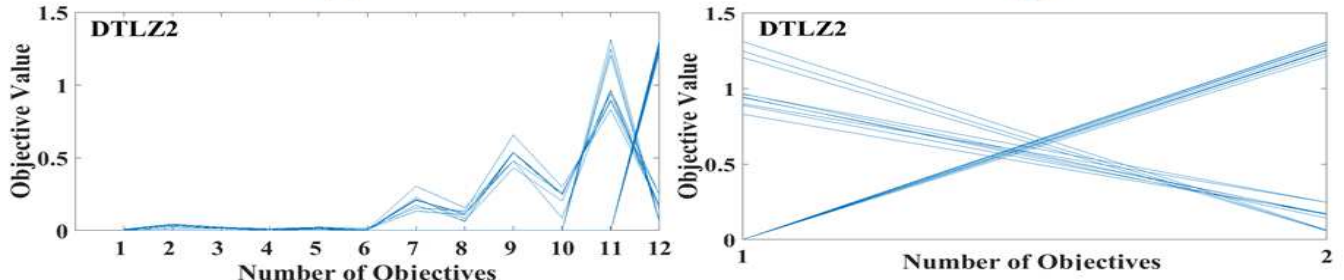

(b)

(h)
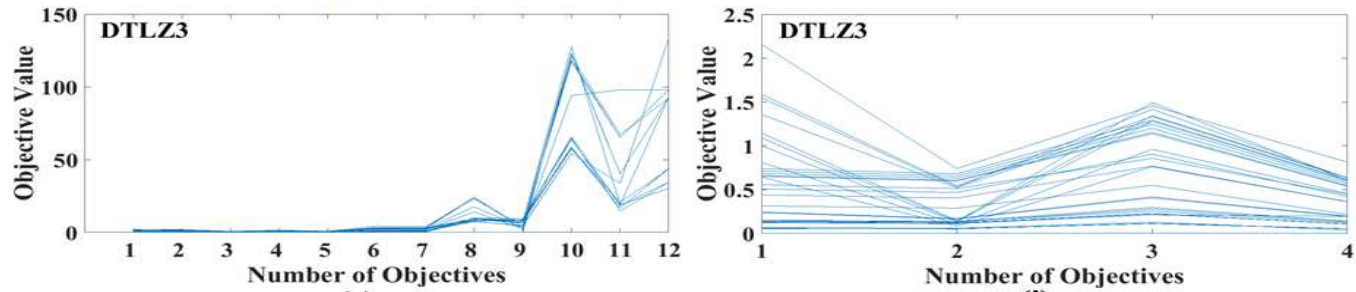

(c)
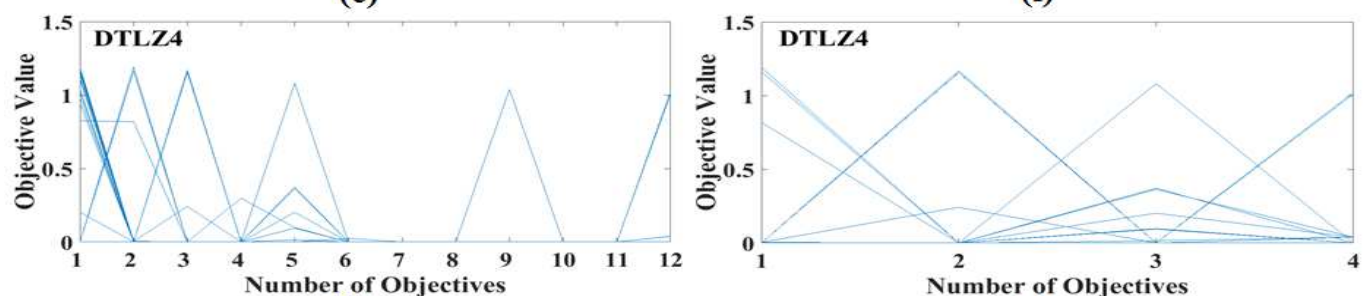

(d)

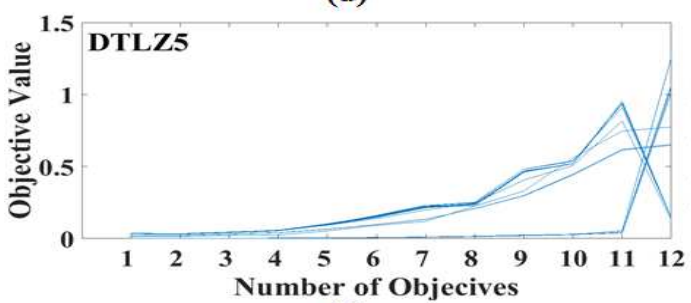

(j)

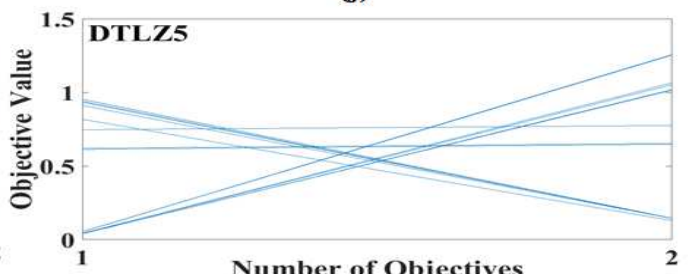

(e)

(k)

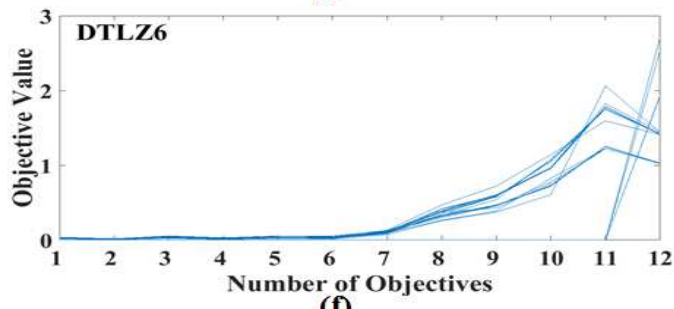

(f)

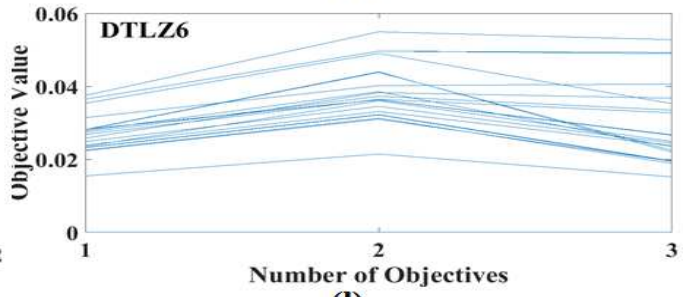

(I)

Fig. 4: Graphical result for DTLZ test suite with 12 objectives from MOSSO: (a-f) Parallel plot of original objective-set, (g-l) Parallel plot of essential objective-set. 

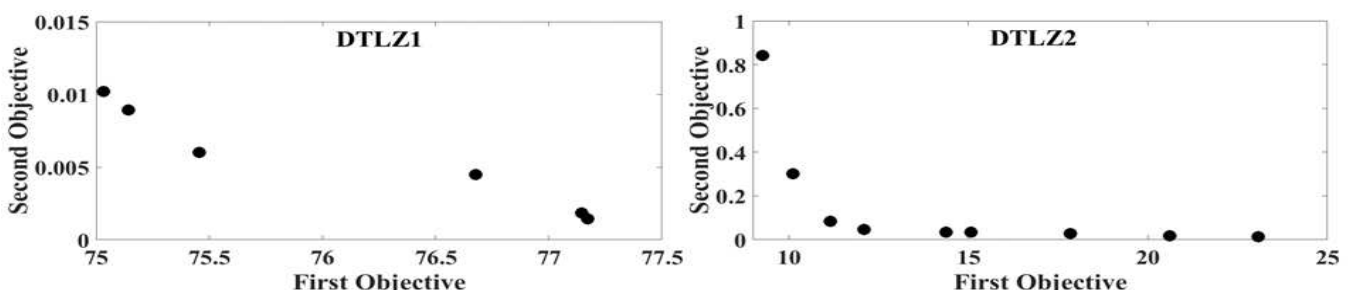

(a)

(b)
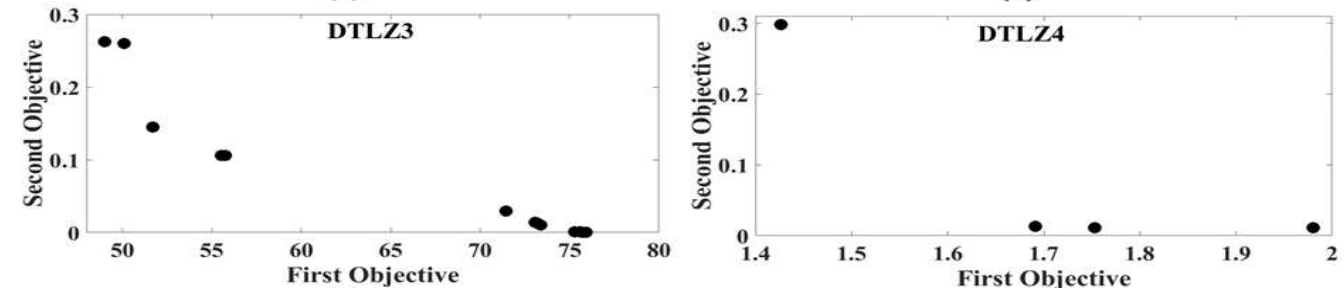

(c)
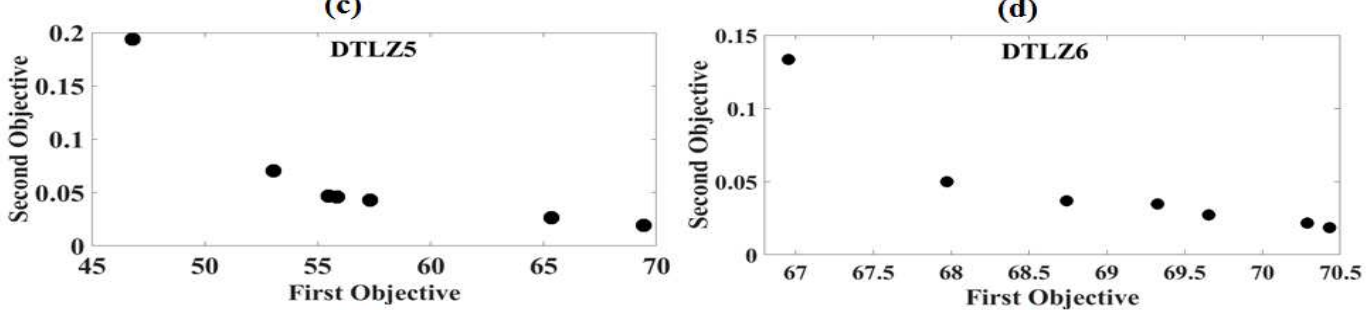

(e)

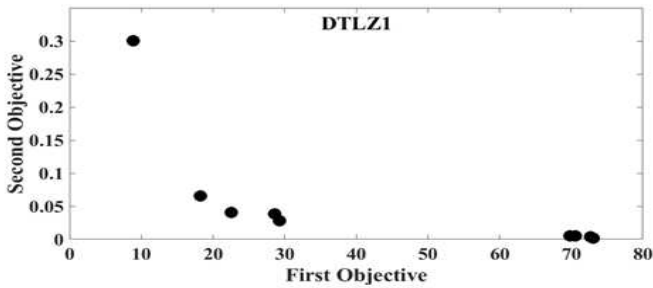

(f)

(g)

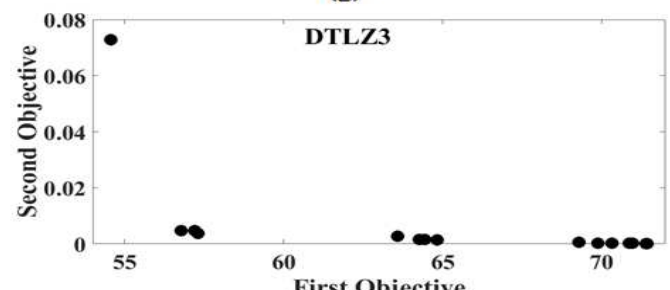

(i)

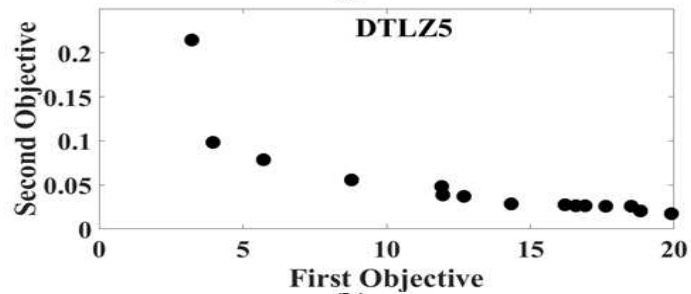

(k)

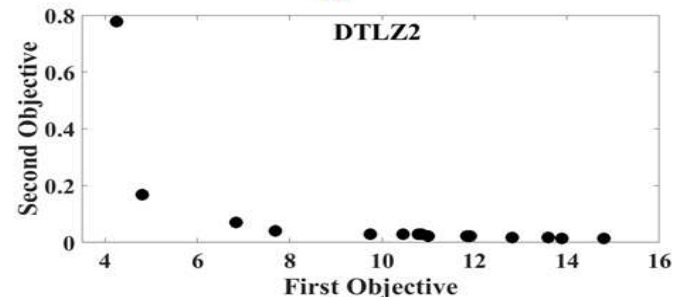

(h)

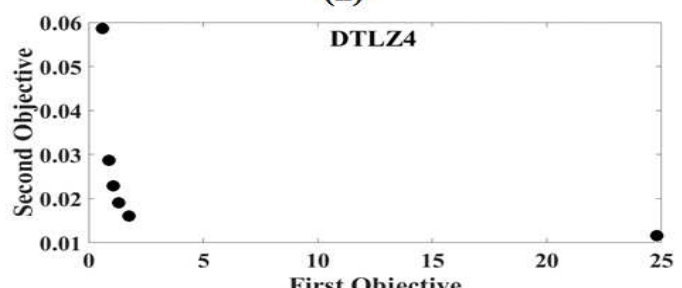

(j)

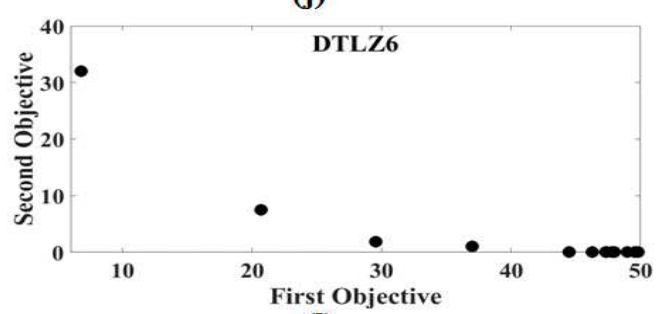

(I)

Fig. 5: Pareto front produced using MOSSO for DTLZ problem: (a-f) 10-objective sample set, (g-1) 12-objective sample set. 

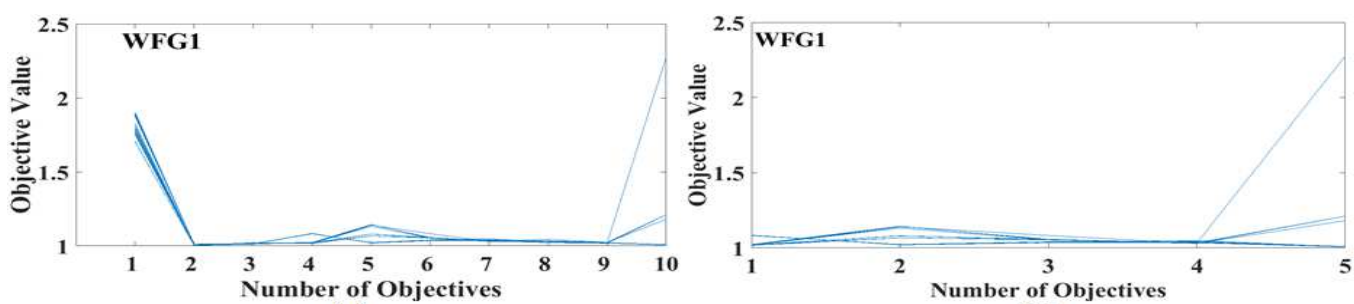

(a)

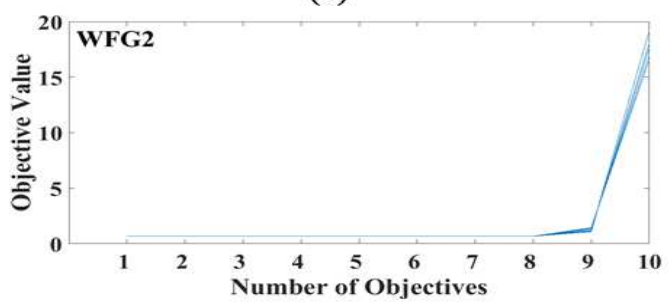

(g)

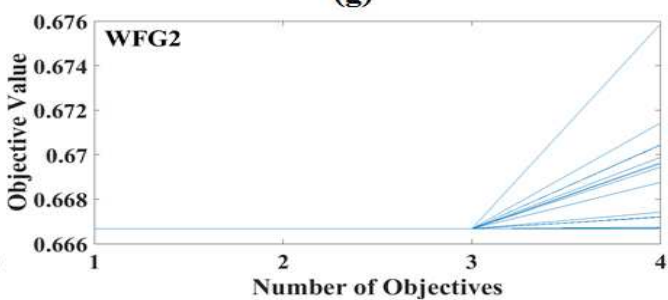

(b)

(h)
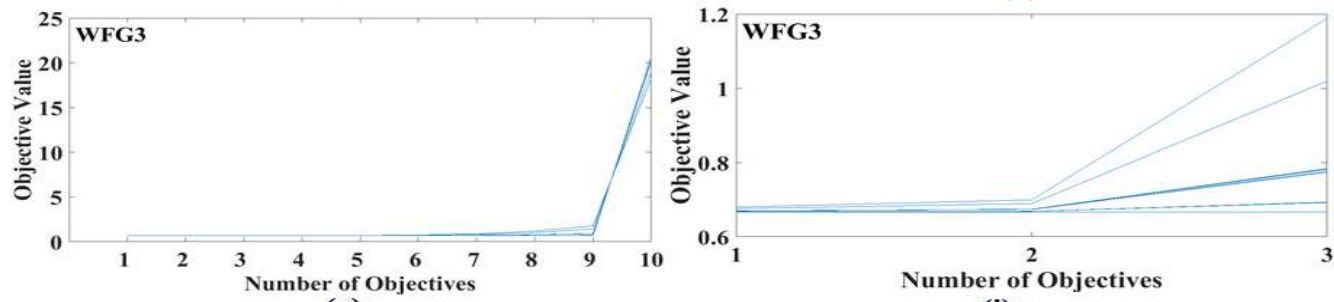

(c)
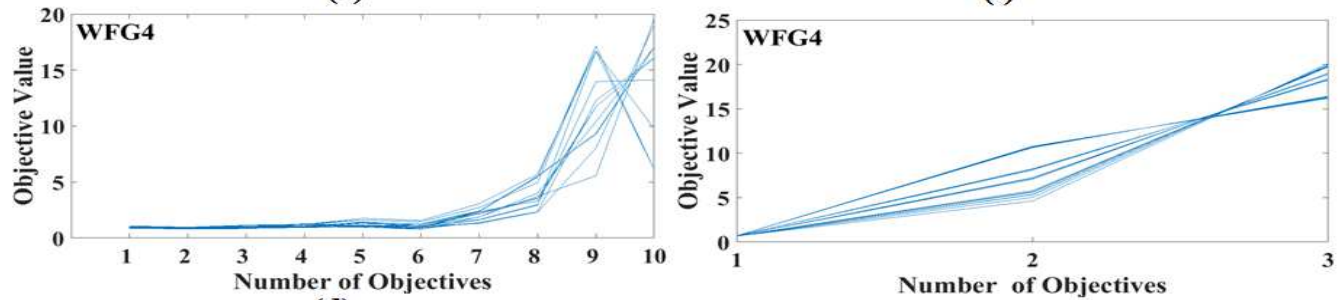

(d)
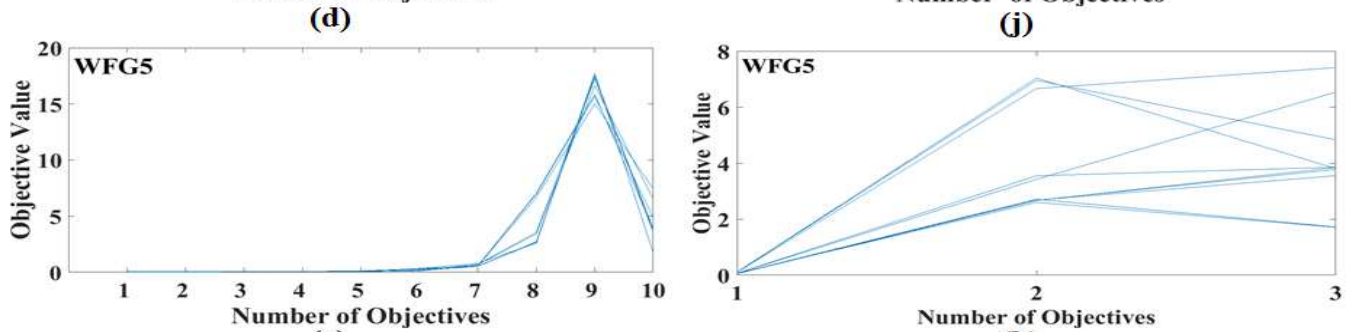

(e)

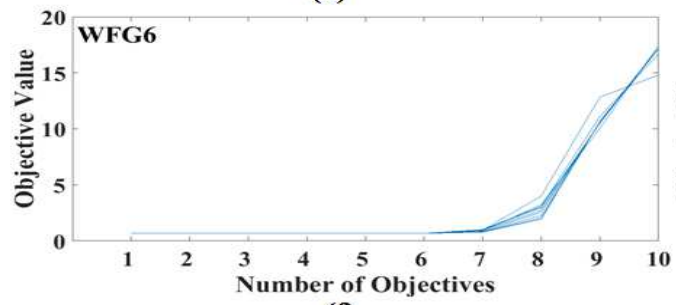

(k)

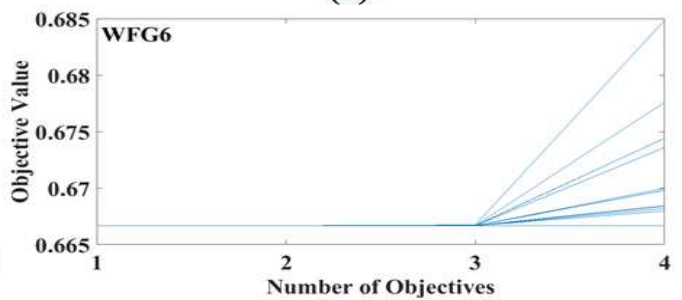

(I)

Fig. 6: Graphical result for WFG test suite with 10 objectives from MOSSO: (a-f) Parallel plot of original objectiveset, (g-1) Parallel plot of essential objective-set. 
Table 4: Mean and standard deviation of HVD performance metric on DTLZ problem for 20 independent runs. Best results are shown in bold font style.

\begin{tabular}{|c|c|c|c|c|c|c|}
\hline \multirow{3}{*}{$\begin{array}{c}\text { Test } \\
\text { Problem }\end{array}$} & \multicolumn{6}{|c|}{ HVD } \\
\hline & \multicolumn{2}{|c|}{ MOSSO-II } & \multicolumn{2}{|c|}{ MOPSO } & \multicolumn{2}{|c|}{ SPEA2 } \\
\hline & Mean & Std. Dev. & Mean & Std. Dev. & Mean & Std. Dev. \\
\hline DTLZ1 & $3.66 \mathrm{E}-01$ & $4.99 \mathrm{E}-03$ & $3.92 \mathrm{E}-01$ & $8.01 \mathrm{E}-02$ & $4.14 \mathrm{E}-01$ & $1.10 \mathrm{E}-01$ \\
\hline DTLZ2 & $9.66 \mathrm{E}-02$ & $2.30 \mathrm{E}-02$ & $3.38 \mathrm{E}-01$ & $4.52 \mathrm{E}-03$ & $2.21 \mathrm{E}-01$ & $1.53 \mathrm{E}-01$ \\
\hline DTLZ3 & $-7.93 \mathrm{E}-03$ & $6.16 \mathrm{E}-03$ & $6.42 \mathrm{E}-03$ & $6.26 \mathrm{E}-03$ & $6.27 \mathrm{E}-01$ & $5.38 \mathrm{E}-03$ \\
\hline DTLZ4 & $0.00 \mathrm{E}+00$ & $0.00 \mathrm{E}+00$ & $-1.22 \mathrm{E}-02$ & $3.859 \mathrm{E}-02$ & $4.77 \mathrm{E}-01$ & 4.87E-01 \\
\hline DTLZ5 & $1.55 \mathrm{E}-03$ & $4.81 \mathrm{E}-04$ & $5.63 \mathrm{E}-03$ & $1.25 \mathrm{E}-02$ & $-1.04 \mathrm{E}-01$ & $2.71 \mathrm{E}-01$ \\
\hline DTLZ6 & $7.97 \mathrm{E}-03$ & $2.58 \mathrm{E}-06$ & $-4.67 \mathrm{E}-02$ & $3.60 \mathrm{E}-02$ & $-8.66 \mathrm{E}-02$ & 4.93E-02 \\
\hline
\end{tabular}

Table 5: Mean and standard deviation of $\Delta$ performance metric on DTLZ problem for 20 independent runs. Best results are shown in bold font style.

\begin{tabular}{|c|c|c|c|c|c|c|}
\hline \multirow{3}{*}{$\begin{array}{c}\text { Test } \\
\text { Problem }\end{array}$} & \multicolumn{6}{|c|}{$\Delta$} \\
\hline & \multicolumn{2}{|c|}{ MOSSO-II } & \multicolumn{2}{|c|}{ MOPSO } & \multicolumn{2}{|c|}{ SPEA2 } \\
\hline & Mean & Std. Dev. & Mean & Std. Dev. & Mean & Std. Dev. \\
\hline DTLZ1 & $1.00 \mathrm{E}+00$ & $0.00 \mathrm{E}+00$ & $1.00 \mathrm{E}+00$ & $0.00 \mathrm{E}+00$ & $1.00 \mathrm{E}+00$ & $0.00 \mathrm{E}+00$ \\
\hline DTLZ2 & $1.00 \mathrm{E}+00$ & $0.00 \mathrm{E}+00$ & 9.99E-01 & $0.00 \mathrm{E}+00$ & 8.92E-01 & $3.14 \mathrm{E}-01$ \\
\hline DTLZ3 & $1.00 \mathrm{E}+00$ & $0.00 \mathrm{E}+00$ & $5.13 \mathrm{E}-01$ & 7.67E-02 & $1.00 \mathrm{E}+00$ & $2.04 \mathrm{E}-16$ \\
\hline DTLZ4 & $8.74 \mathrm{E}-01$ & $2.28 \mathrm{E}-16$ & $8.20 \mathrm{E}-03$ & $2.21 \mathrm{E}-03$ & 7.07E-01 & $1.57 \mathrm{E}-01$ \\
\hline DTLZ5 & $7.45 \mathrm{E}-01$ & $2.28 \mathrm{E}-16$ & $7.20 \mathrm{E}-01$ & 7.92E-02 & $5.09 \mathrm{E}-01$ & $2.20 \mathrm{E}-01$ \\
\hline DTLZ6 & $3.44 \mathrm{E}-02$ & $2.10 \mathrm{E}-02$ & $1.81 \mathrm{E}-02$ & $2.02 \mathrm{E}-02$ & $2.23 \mathrm{E}-02$ & $2.13 \mathrm{E}-02$ \\
\hline
\end{tabular}

approach is compared with the result of many-objective NSGA-III algorithm. Further, the performance is evaluated on different satellite images in terms Davies-Bouldin performance index and classification error percentage. This validates the accuracy of clustering performance to handle MaOPs in practical application with obtained essential objectives over the original objective set.

\subsection{Database}

Two image data of Landsat 8 is utilized because it consists band 9 (quality band) which contains the information of cloud contaminated regions. Both the data are stacked with Band 6 (shortwave infrared (SWIR)), Band 5 (near infrared (NIR)) and Band 4 (Red) for experiment purpose because of their large spectral difference between various earth's surfaces and cloud.

- Image I $_{1}$ The target image was taken on $8^{\text {th }}$ March, 2017 which shows the presence of various earth's surfaces with cloud. Therefore, the whole image is divided into three sub images where the portion of cloud is present over water $\left(\operatorname{Image}_{1 w}\right)$, vegetation $\left(\right.$ Image $\left._{1 v}\right)$ and soil (Image $\left.e_{1 s}\right)$ regions, individually.
This is represented in Fig. 9 for better understanding purpose.

1. Image $e_{1 w}$ has 104280 samples from $65^{0} 37^{\prime} 47.59^{\prime \prime} \mathrm{W}$ to $65^{0} 31^{\prime} 18.51^{\prime \prime} \mathrm{W}$ and from $9^{0} 26^{\prime} 25.44^{\prime \prime} \mathrm{N}$ to $9^{0} 22^{\prime} 11.62^{\prime \prime}$ $\mathrm{N}$ which is composite of majorly water and cloudy regions.

2. Image $e_{1 v}$ has 139524 samples from $65^{0} 3^{\prime} 57.75^{\prime \prime} \mathrm{W}$ to $64^{0} 56^{\prime} 32.40^{\prime \prime} \mathrm{W}$ and from $8^{0} 55^{\prime} 34.35^{\prime \prime} \mathrm{N}$ to $8^{0} 50^{\prime} 37.02^{\prime \prime}$ $\mathrm{N}$ which is composite of majorly vegetation and cloudy regions.

3. Image Is $_{1 s}$ has 139524 samples from $66^{0} 5^{\prime} 16.39^{\prime \prime} \mathrm{W}$ to $65^{0} 57^{\prime} 51.08^{\prime \prime} \mathrm{W}$ and from $8^{0} 34^{\prime} 18.20^{\prime \prime} \mathrm{N}$ to $8^{0} 29^{\prime} 22.17^{\prime \prime}$ $\mathrm{N}$ which is composite of majorly soil and cloudy regions.

- Image $e_{2}$ The target image was taken on $16^{\text {th }}$ June, 2019 which shows the presence of various earth's surfaces with cloud.

1. Image $2 w$ has 522729 samples from $157^{0} 11^{\prime} 53.11^{\prime \prime}$ $\mathrm{W}$ to $156^{0} 59^{\prime} 27.30^{\prime \prime} \mathrm{W}$ and from $22^{0} 8^{\prime} 35.23^{\prime \prime} \mathrm{N}$ to $21^{0} 56^{\prime} 42.35^{\prime \prime} \mathrm{N}$ which is composite of majorly water and cloudy regions.

2. Image $2 v$ has 377554 samples from $158^{0} 2^{\prime} 15.23^{\prime \prime} \mathrm{W}$ to $157^{0} 56^{\prime} 21.66^{\prime \prime} \mathrm{W}$ and from $21^{0} 34^{\prime} 30.51^{\prime \prime} \mathrm{N}$ to 


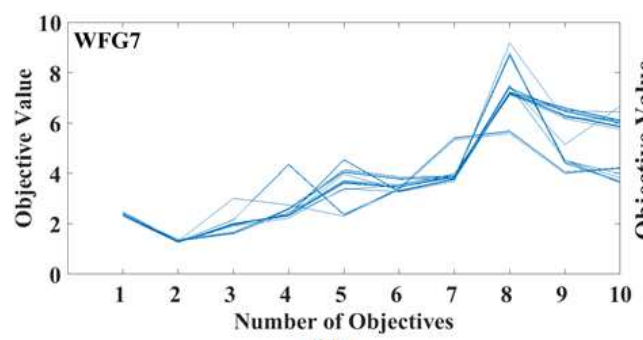

(a)

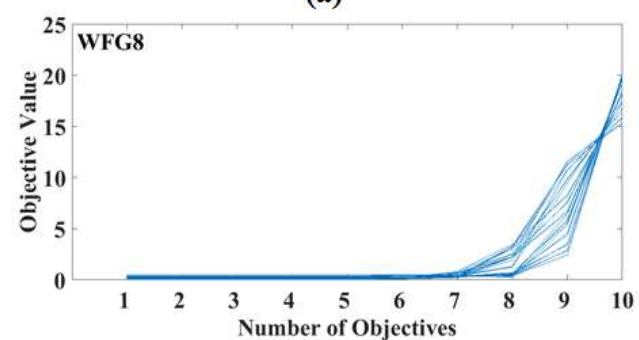

(b)

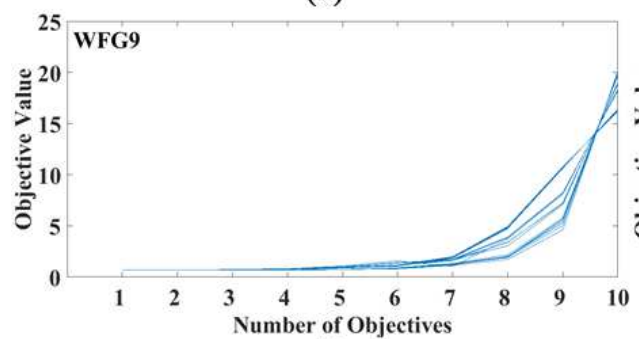

(c)

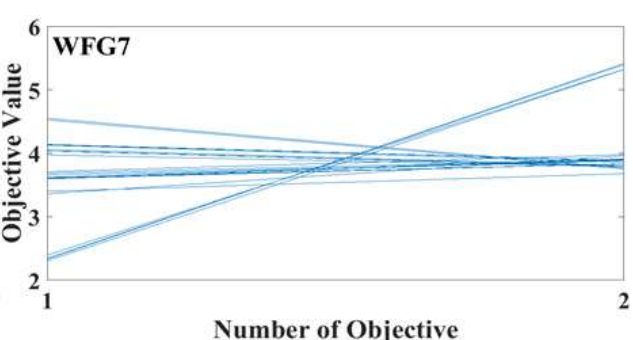

(d)

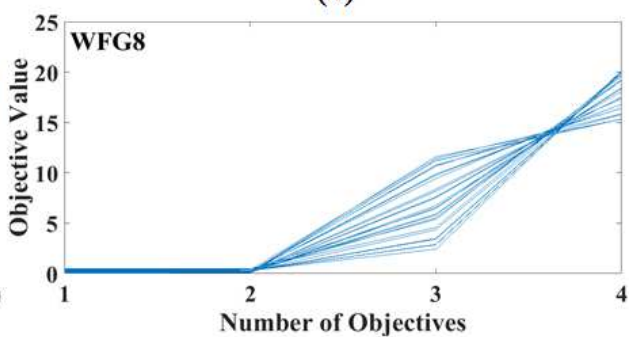

(e)

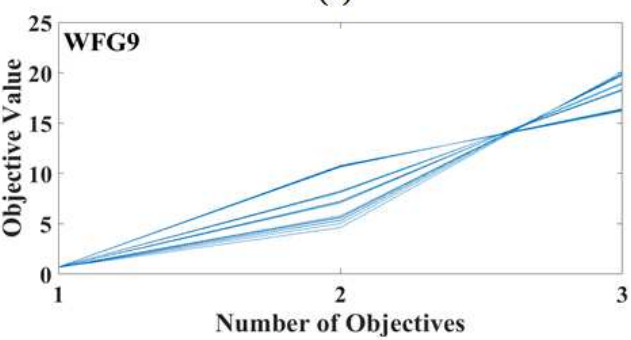

(f)

Fig. 7: Graphical result for WFG test suite with 10 objectives from MOSSO: $(\mathrm{a}-\mathrm{c})$ Parallel plot of original objectiveset, (d-f) Parallel plot of essential objective-set.

$21^{0} 24^{\prime} 34.23^{\prime \prime} \mathrm{N}$ which is composite of majorly vegetation and cloudy regions.

3. Image $_{2 s}$ has 522729 samples from $158^{0} 8^{\prime} 49.25^{\prime \prime} \mathrm{W}$ to $157^{0} 56^{\prime} 21.66^{\prime \prime} \mathrm{W}$ and from $21^{0} 29^{\prime} 22.38^{\prime \prime} \mathrm{N}$ to $21^{0} 17^{\prime} 33.66^{\prime \prime} \mathrm{N}$ which is composite of majorly soil and cloudy regions.

\subsection{Analysis of cloud detection}

This section reports the performance of MOSSO approach in cloud detection of multi-spectral satellite image. The proposed approach incorporates five objective functions which are simultaneously optimized to perform clustering. The algorithm begins with initializing position of each individual as cluster centroid vectors. The parameters of the proposed approach are as under: Population size is 30 and number of generation is 50. To show the effectiveness of the algorithm, it is verified visually by comparing the result with quality image and statistically by classification error percentage.

\subsubsection{Objective function to handle cluster problem}

The cluster technique divides the entire data into $c$ classes in such a way that most similar data points remain in same cluster whereas those data points which are maximum uncorrelated belong to different clusters. The following are five important functions which have been taken from original MOSSO paper (Gupta et al., 2019) and (Gupta and Nanda, 2019b) to solve many-objective cluster problem.

1. Similarity measure (SM): $S M$ reflects the computation of similarity among the data points to solve clustering problems. The maximum value of SM reports better clustering efficiency of the algorithm. The mathematical formulation of $S M$ is,

$S M=-\sum_{i=1}^{k} \sum_{j=1}^{c} \sqrt{\left(C_{i}-C_{j}\right)^{2}}$

Where, $\mathrm{k}$ is $\frac{c !}{(c-2) ! 2 !}$ and $\mathrm{C}$ is the centroid of classes.

2. Variance measure (VAR): The VAR measures the spread of the target data in order to measure the compactness of the cluster. Eq. 12 represents the 

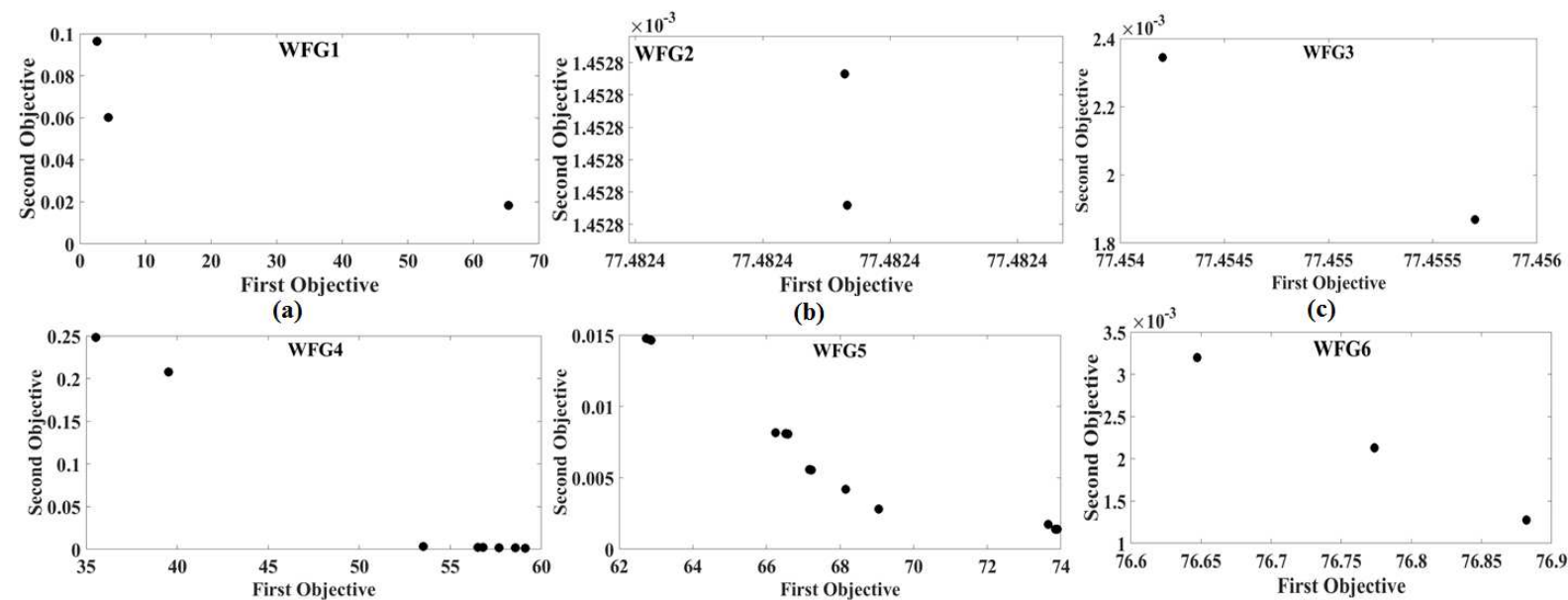

(b)
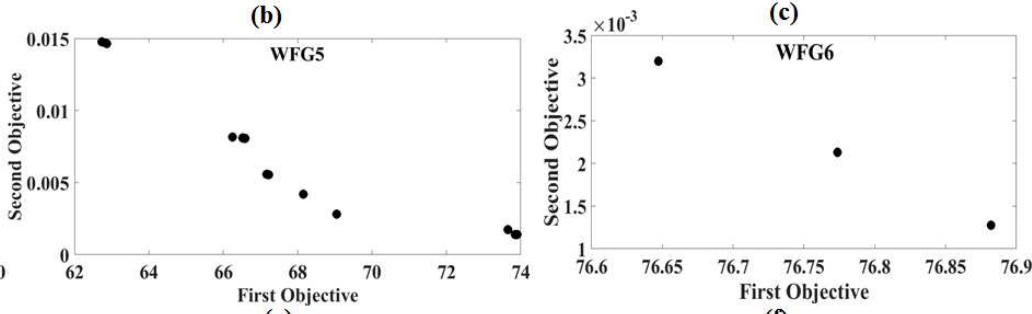

(d)

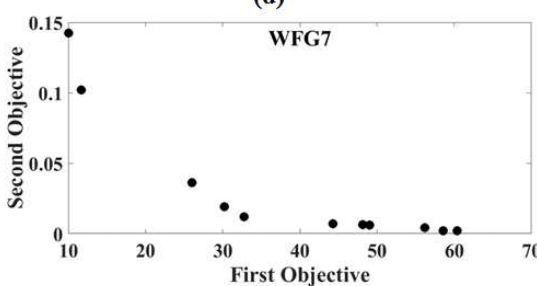

(e)

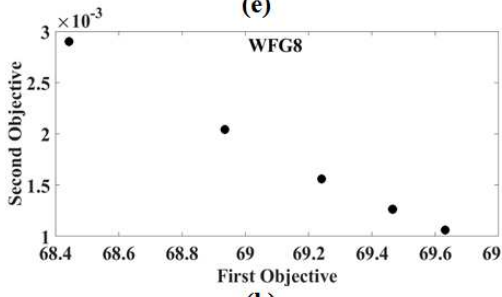

(f)

(g)

(h)

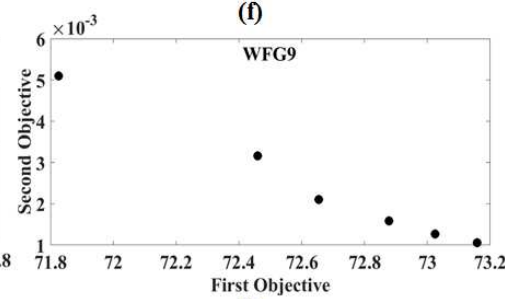

(i)

Fig. 8: Pareto front for WFG test suite with 10 objectives

Table 6: Mean and standard deviation of IGD performance metric on WFG problem for 20 independent runs. Best results are shown in bold font style.

\begin{tabular}{|c|c|c|c|c|c|c|c|}
\hline \multirow{3}{*}{$\begin{array}{c}\text { Test } \\
\text { Problem }\end{array}$} & \multicolumn{7}{|c|}{ IGD } \\
\hline & \multirow{2}{*}{ M } & \multicolumn{2}{|c|}{ MOSSO } & \multicolumn{2}{|c|}{ MOPSO } & \multicolumn{2}{|c|}{ SPEA2 } \\
\hline & & Mean & Std. Dev. & Mean & Std. Dev. & Mean & Std. Dev. \\
\hline \multirow{2}{*}{ WFG1 } & 10 & $1.44 \mathrm{E}-02$ & $9.62 \mathrm{E}-05$ & $1.47 \mathrm{E}-02$ & $9.00 \mathrm{E}-05$ & $1.46 \mathrm{E}-02$ & $1.17 \mathrm{E}-04$ \\
\hline & 12 & $1.41 \mathrm{E}-02$ & $3.66 \mathrm{E}-18$ & $1.29 \mathrm{E}-01$ & $1.24 \mathrm{E}-05$ & $1.41 \mathrm{E}-02$ & $2.15 \mathrm{E}-06$ \\
\hline \multirow{2}{*}{ WFG2 } & 10 & $6.87 \mathrm{E}-03$ & $1.08 \mathrm{E}-03$ & $5.32 \mathrm{E}-02$ & 7.19E-03 & $7.13 \mathrm{E}-03$ & $8.08 \mathrm{E}-04$ \\
\hline & 12 & $6.34 \mathrm{E}-03$ & 7.77E-04 & $6.83 \mathrm{E}-03$ & $1.04 \mathrm{E}-03$ & $6.34 \mathrm{E}-03$ & $9.14 \mathrm{E}-19$ \\
\hline \multirow{2}{*}{ WFG3 } & 10 & $6.87 \mathrm{E}-03$ & $1.35 \mathrm{E}-03$ & $6.53 \mathrm{E}-02$ & $6.73 \mathrm{E}-03$ & $7.64 \mathrm{E}-03$ & $1.23 \mathrm{E}-03$ \\
\hline & 12 & $6.76 \mathrm{E}-03$ & $1.22 \mathrm{E}-02$ & $1.74 \mathrm{E}-02$ & $1.44 \mathrm{E}-02$ & $1.41 \mathrm{E}-02$ & $1.28 \mathrm{E}-02$ \\
\hline \multirow{2}{*}{ WFG4 } & 10 & $1.18 \mathrm{E}-02$ & $3.42 \mathrm{E}-04$ & $2.43 \mathrm{E}-02$ & $2.29 \mathrm{E}-02$ & $2.74 \mathrm{E}-02$ & $1.98 \mathrm{E}-02$ \\
\hline & 12 & $1.08 \mathrm{E}-02$ & $1.17 \mathrm{E}-03$ & $1.05 \mathrm{E}-02$ & 8.97E-04 & $1.11 \mathrm{E}-02$ & 7.53E-04 \\
\hline \multirow{2}{*}{ WFG5 } & 10 & $1.04 \mathrm{E}-03$ & $8.99 \mathrm{E}-03$ & $2.86 \mathrm{E}-02$ & $2.68 \mathrm{E}-03$ & $2.54 \mathrm{E}-02$ & 7.33E-03 \\
\hline & 12 & $1.34 \mathrm{E}-03$ & $1.34 \mathrm{E}-03$ & $9.28 \mathrm{E}-03$ & $5.63 \mathrm{E}-03$ & $4.59 \mathrm{E}-03$ & $5.28 \mathrm{E}-03$ \\
\hline \multirow{2}{*}{ WFG6 } & 10 & $6.87 \mathrm{E}-03$ & $4.89 \mathrm{E}-02$ & 7.04E-02 & $3.45 \mathrm{E}-02$ & $6.15 \mathrm{E}-02$ & $4.56 \mathrm{E}-02$ \\
\hline & 12 & $6.87 \mathrm{E}-03$ & $1.48 \mathrm{E}-02$ & $2.26 \mathrm{E}-02$ & $1.82 \mathrm{E}-02$ & $1.633 \mathrm{E}-02$ & $1.45 \mathrm{E}-02$ \\
\hline \multirow{2}{*}{ WFG7 } & 10 & $2.93 \mathrm{E}-02$ & $1.38 \mathrm{E}-02$ & $3.94 \mathrm{E}-02$ & $7.26 \mathrm{E}-03$ & $4.09 \mathrm{E}-02$ & $6.05 \mathrm{E}-03$ \\
\hline & 12 & $1.09 \mathrm{E}-02$ & $4.04 \mathrm{E}-02$ & $5.71 \mathrm{E}-02$ & $4.01 \mathrm{E}-02$ & $5.13 \mathrm{E}-02$ & $2.86 \mathrm{E}-02$ \\
\hline \multirow{2}{*}{ WFG8 } & 10 & $2.04 \mathrm{E}-03$ & $1.15 \mathrm{E}-02$ & $1.82 \mathrm{E}-02$ & $9.92 \mathrm{E}-03$ & $1.37 \mathrm{E}-02$ & $1.12 \mathrm{E}-02$ \\
\hline & 12 & $2.17 \mathrm{E}-03$ & $1.16 \mathrm{E}-02$ & $2.16 \mathrm{E}-02$ & $2.04 \mathrm{E}-02$ & $2.78 \mathrm{E}-02$ & $1.57 \mathrm{E}-02$ \\
\hline \multirow{2}{*}{ WFG9 } & 10 & $1.84 \mathrm{E}-02$ & $1.19 \mathrm{E}-02$ & $2.70 \mathrm{E}-02$ & $1.73 \mathrm{E}-02$ & $2.60 \mathrm{E}-02$ & $1.46 \mathrm{E}-02$ \\
\hline & 12 & $1.07 \mathrm{E}-02$ & $1.30 \mathrm{E}-02$ & $2.36 \mathrm{E}-02$ & $1.11 \mathrm{E}-02$ & $2.46 \mathrm{E}-02$ & $9.95 \mathrm{E}-03$ \\
\hline
\end{tabular}


Table 7: Mean and standard deviation of SP performance metric on WFG problem for 20 independent runs. Best results are shown in bold font style.

\begin{tabular}{|c|c|c|c|c|c|c|c|}
\hline \multirow{3}{*}{$\begin{array}{c}\text { Test } \\
\text { Problem }\end{array}$} & \multirow{3}{*}{ M } & \multicolumn{6}{|c|}{ SP } \\
\hline & & \multicolumn{2}{|c|}{ MOSSO } & \multicolumn{2}{|c|}{ MOPSO } & \multicolumn{2}{|c|}{ SPEA2 } \\
\hline & & Mean & Std. Dev. & Mean & Std. Dev. & Mean & Std. Dev. \\
\hline \multirow{2}{*}{ WFG1 } & 10 & $2.23 \mathrm{E}-04$ & $3.36 \mathrm{E}-04$ & $3.51 \mathrm{E}-04$ & $2.13 \mathrm{E}-04$ & $5.53 \mathrm{E}-04$ & $3.45 \mathrm{E}-04$ \\
\hline & 12 & $1.68 \mathrm{E}-04$ & $1.97 \mathrm{E}-04$ & $1.23 \mathrm{E}-02$ & $2.24 \mathrm{E}-01$ & $1.77 \mathrm{E}-01$ & $2.84 \mathrm{E}-01$ \\
\hline \multirow{2}{*}{ WFG2 } & 10 & $1.53 \mathrm{E}-05$ & $4.82 \mathrm{E}-05$ & $1.78 \mathrm{E}-05$ & $3.55 \mathrm{E}-05$ & $1.55 \mathrm{E}-05$ & $4.89 \mathrm{E}-5$ \\
\hline & 12 & $1.31 \mathrm{E}-04$ & $2.86 \mathrm{E}-20$ & $1.33 \mathrm{E}-04$ & $2.86 \mathrm{E}-20$ & $1.31 \mathrm{E}-04$ & $2.86 \mathrm{E}-20$ \\
\hline \multirow{2}{*}{ WFG3 } & 10 & $2.94 \mathrm{E}-04$ & $6.15 \mathrm{E}-04$ & $6.89 \mathrm{E}-05$ & $4.86 \mathrm{E}-04$ & $6.04 E-06$ & 5.97E-06 \\
\hline & 12 & $1.25 \mathrm{E}-04$ & $1.63 \mathrm{E}-04$ & $1.14 \mathrm{E}-04$ & $1.19 \mathrm{E}-04$ & $8.64 \mathrm{E}-05$ & $1.17 \mathrm{E}-04$ \\
\hline \multirow{2}{*}{ WFG4 } & 10 & $5.35 \mathrm{E}-03$ & $1.94 \mathrm{E}-03$ & $3.19 \mathrm{E}-02$ & $6.50 \mathrm{E}-02$ & $3.17 \mathrm{E}-02$ & $5.28 \mathrm{E}-02$ \\
\hline & 12 & $2.20 \mathrm{E}-02$ & $7.06 \mathrm{E}-03$ & $1.15 \mathrm{E}-02$ & $2.54 \mathrm{E}-03$ & $1.18 \mathrm{E}-02$ & $6.29 \mathrm{E}-03$ \\
\hline \multirow{2}{*}{ WFG5 } & 10 & $4.44 \mathrm{E}-02$ & $4.54 \mathrm{E}-02$ & $5.14 \mathrm{E}-02$ & $4.15 \mathrm{E}-02$ & $2.18 \mathrm{E}-02$ & $3.16 \mathrm{E}-02$ \\
\hline & 12 & $2.60 \mathrm{E}-02$ & $3.55 \mathrm{E} 0-2$ & $1.11 \mathrm{E}-02$ & $4.97 \mathrm{E}-03$ & $6.86 \mathrm{E}-03$ & $6.53 \mathrm{E}-03$ \\
\hline \multirow{2}{*}{ WFG6 } & 10 & $7.45 \mathrm{E}-03$ & $1.00 \mathrm{E}-02$ & $1.37 \mathrm{E}-02$ & $8.48 \mathrm{E}-03$ & $1.26 \mathrm{E}-02$ & $9.39 \mathrm{E}-03$ \\
\hline & 12 & $6.08 \mathrm{E}-03$ & $1.28 \mathrm{E}-02$ & $1.21 \mathrm{E}-02$ & $1.57 \mathrm{E}-02$ & $6.08 \mathrm{E}-03$ & $1.28 \mathrm{E}-02$ \\
\hline \multirow{2}{*}{ WFG7 } & 10 & $1.60 \mathrm{E}-02$ & $1.19 \mathrm{E}-02$ & $2.06 \mathrm{E}-02$ & $1.59 \mathrm{E}-02$ & $2.42 \mathrm{E}-02$ & $1.30 \mathrm{E}-02$ \\
\hline & 12 & $7.11 \mathrm{E}-02$ & $6.38 \mathrm{E}-02$ & $7.90 \mathrm{E}-02$ & $5.95 \mathrm{E}-02$ & $7.38 \mathrm{E}-02$ & $4.54 \mathrm{E}-02$ \\
\hline \multirow{2}{*}{ WFG8 } & 10 & 1.57E-02 & $1.40 \mathrm{E}-02$ & $2.58 \mathrm{E}-02$ & $1.03 \mathrm{E}-02$ & $2.04 \mathrm{E}-02$ & $1.27 \mathrm{E}-02$ \\
\hline & 12 & $7.95 \mathrm{E}-03$ & $1.07 \mathrm{E}-02$ & $6.90 \mathrm{E}-02$ & $7.67 \mathrm{E}-02$ & 8.97E-02 & $4.77 \mathrm{E}-02$ \\
\hline \multirow{2}{*}{ WFG9 } & 10 & $1.67 \mathrm{E}-02$ & $1.34 \mathrm{E}-03$ & $1.12 \mathrm{E}-02$ & $7.70 \mathrm{E}-03$ & $1.38 \mathrm{E}-02$ & $5.31 \mathrm{E}-03$ \\
\hline & 12 & $8.01 \mathrm{E}-03$ & $8.37 \mathrm{E}-03$ & $7.11 \mathrm{E}-03$ & $8.20 \mathrm{E}-03$ & $6.42 \mathrm{E}-03$ & $7.22 \mathrm{E}-03$ \\
\hline
\end{tabular}

Table 8: Mean and standard deviation of $\Delta$ performance metric on WFG problem for 20 independent runs. Best results are shown in bold font style.

\begin{tabular}{|c|c|c|c|c|c|c|c|}
\hline \multirow{3}{*}{$\begin{array}{c}\text { Test } \\
\text { Problem }\end{array}$} & \multirow{3}{*}{ M } & \multicolumn{6}{|c|}{$\Delta$} \\
\hline & & \multicolumn{2}{|c|}{ MOSSO } & \multicolumn{2}{|c|}{ MOPSO } & \multicolumn{2}{|c|}{ SPEA2 } \\
\hline & & Mean & Std. Dev. & Mean & Std. Dev. & Mean & Std. Dev. \\
\hline \multirow{2}{*}{ WFG1 } & 10 & $1.08 \mathrm{E}+00$ & $8.11 \mathrm{E}+00$ & $1.07 \mathrm{E}+00$ & $6.73 \mathrm{E}-03$ & $1.07 \mathrm{E}+00$ & $9.09 \mathrm{E}-03$ \\
\hline & 12 & $1.02 \mathrm{E}+00$ & $0.00 \mathrm{E}+00$ & $1.05 \mathrm{E}-01$ & $1.43 \mathrm{E}-04$ & $1.00 \mathrm{E}+00$ & $1.52 \mathrm{E}-04$ \\
\hline \multirow{2}{*}{ WFG2 } & 10 & $3.51 \mathrm{E}-01$ & $5.00 \mathrm{E}-03$ & $2.24 \mathrm{E}-01$ & $3.27 \mathrm{E}-03$ & $3.43 \mathrm{E}-01$ & $4.13 \mathrm{E}-03$ \\
\hline & 12 & $2.53 \mathrm{E}-01$ & $3.95 \mathrm{E}-03$ & $2.56 \mathrm{E}-01$ & $4.61 \mathrm{E}-03$ & $2.52 \mathrm{E}-01$ & $2.07 \mathrm{E}-03$ \\
\hline \multirow{2}{*}{ WFG3 } & 10 & $3.48 \mathrm{E}-01$ & $5.90 \mathrm{E}-03$ & $3.25 \mathrm{E}-01$ & $4.64 \mathrm{E}-03$ & $3.45 \mathrm{E}-01$ & $5.73 \mathrm{E}-03$ \\
\hline & 12 & $1.27 \mathrm{E}+00$ & $1.79 \mathrm{E}+00$ & $1.66 \mathrm{E}+00$ & $2.08 \mathrm{E}+00$ & $1.20 \mathrm{E}+00$ & $1.83 \mathrm{E}+00$ \\
\hline \multirow{2}{*}{ WFG4 } & 10 & 7.67E-01 & $3.57 \mathrm{E}-02$ & $2.32 \mathrm{E}+00$ & $2.89 \mathrm{E}+00$ & $2.89 \mathrm{E}+00$ & $2.60 \mathrm{E}+00$ \\
\hline & 12 & $5.89 \mathrm{E}-01$ & $2.97 \mathrm{E}-02$ & $5.47 \mathrm{E}-01$ & $1.07 \mathrm{E}-02$ & $5.57 \mathrm{E}-01$ & $1.88 \mathrm{E}-02$ \\
\hline \multirow{2}{*}{ WFG5 } & 10 & $2.91 \mathrm{E}+00$ & $1.02 \mathrm{E}+00$ & $3.25 \mathrm{E}+00$ & $2.61 \mathrm{E}-01$ & $2.81 \mathrm{E}+00$ & $9.94 \mathrm{E}-01$ \\
\hline & 12 & $3.93 E+00$ & $4.28 \mathrm{E}+00$ & $8.65 \mathrm{E}-01$ & $4.57 \mathrm{E}-01$ & $4.47 \mathrm{E}-01$ & $4.56 \mathrm{E}-01$ \\
\hline \multirow{2}{*}{ WFG6 } & 10 & $5.70 \mathrm{E}+00$ & $6.91 \mathrm{E}+00$ & $7.26 \mathrm{E}+00$ & $2.25 \mathrm{E}+00$ & $7.76 \mathrm{E}+00$ & $6.37 \mathrm{E}+00$ \\
\hline & 12 & $1.38 \mathrm{E}+00$ & $2.16 \mathrm{E}+00$ & $2.40 \mathrm{E}+00$ & $2.65 \mathrm{E}+00$ & $1.38 \mathrm{E}+00$ & $2.167 \mathrm{E}+00$ \\
\hline \multirow{2}{*}{ WFG7 } & 10 & $5.17 \mathrm{E}+00$ & $1.63 \mathrm{E}+00$ & $4.52 \mathrm{E}+00$ & $1.10 \mathrm{E}+00$ & $4.54 \mathrm{E}+00$ & $7.22 \mathrm{E}-01$ \\
\hline & 12 & $5.57 \mathrm{E}+00$ & $4.92 \mathrm{E}+00$ & $6.36 \mathrm{E}+00$ & $4.87 \mathrm{E}+00$ & $5.39 \mathrm{E}+00$ & $3.41 \mathrm{E}+00$ \\
\hline \multirow{2}{*}{ WFG8 } & 10 & $1.66 \mathrm{E}+00$ & $9.98 \mathrm{E}-01$ & $2.21 \mathrm{E}+00$ & $9.88 \mathrm{E}+00$ & $1.82 \mathrm{E}+00$ & $1.05 \mathrm{E}+00$ \\
\hline & 12 & $1.01 \mathrm{E}+00$ & $1.37 \mathrm{E}+00$ & $2.75 \mathrm{E}+00$ & $2.30 \mathrm{E}+00$ & $3.25 \mathrm{E}+00$ & $2.15 \mathrm{E}+00$ \\
\hline \multirow{2}{*}{ WFG9 } & 10 & $5.06 \mathrm{E}+00$ & $1.74 \mathrm{E}+00$ & $2.99 \mathrm{E}+00$ & $2.56 \mathrm{E}+00$ & $2.85 \mathrm{E}+00$ & $2.14 \mathrm{E}+00$ \\
\hline & 12 & $2.61 \mathrm{E}+00$ & $1.91 \mathrm{E}+00$ & $2.44 \mathrm{E}+00$ & $1.62 \mathrm{E}+00$ & $2.56 \mathrm{E}+00$ & $1.42 \mathrm{E}+00$ \\
\hline
\end{tabular}

formulation of VAR which represents better clus-

tering performance with maximum $V A R$ value.

$$
\begin{array}{r}
V A R=\sum_{i=1}^{n} \min _{j \in\{1,2, \ldots, c\}}\left\{\sum_{j=1}^{c}\left(x_{i}-C_{j}\right)^{2}\right\}, \\
i \in\{1,2, \ldots, n\}
\end{array}
$$




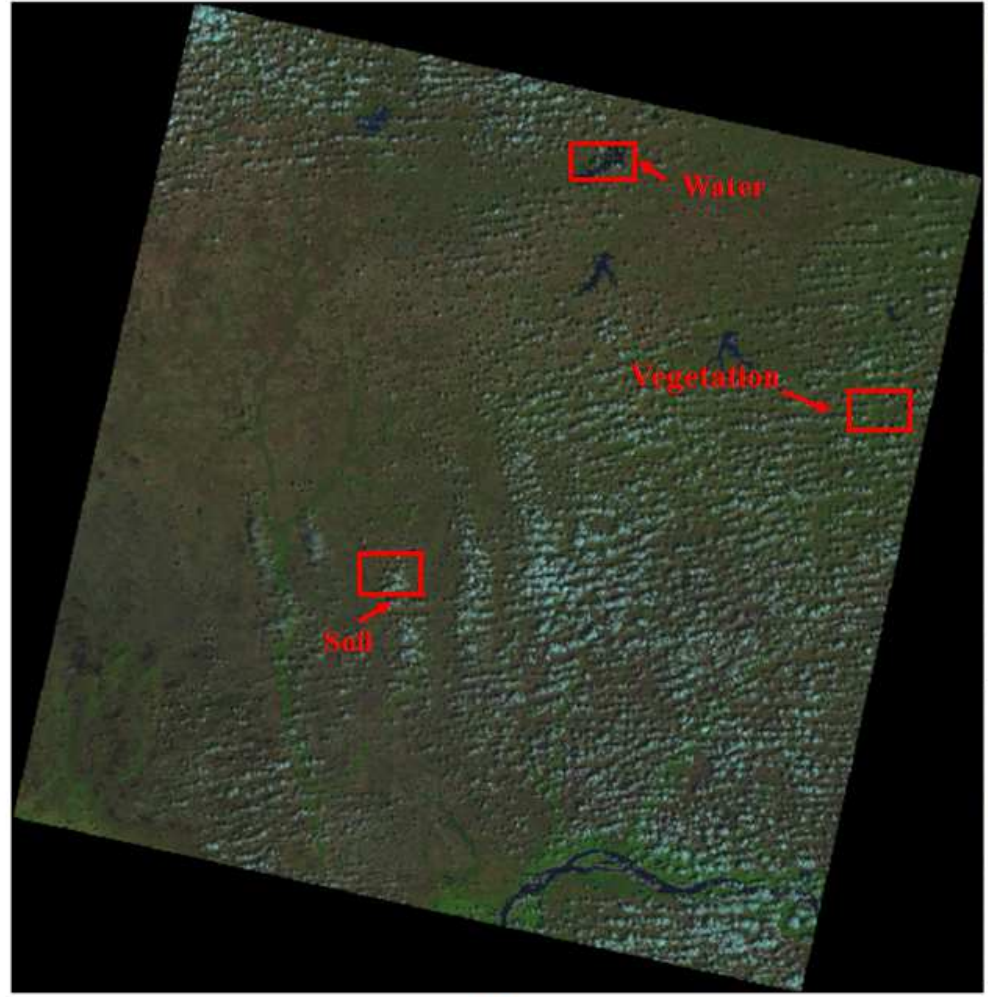

(a)

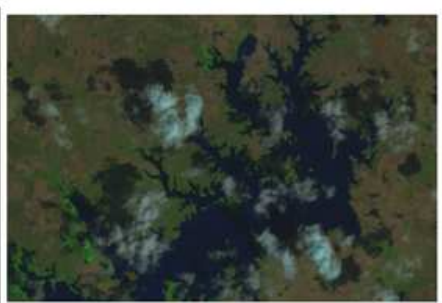

(b)

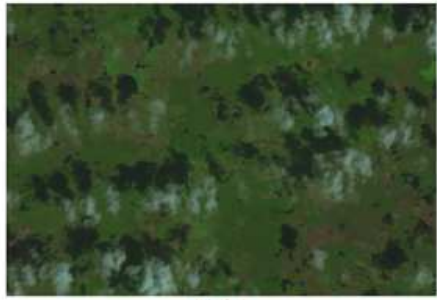

(c)

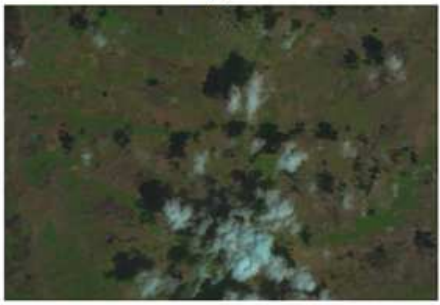

(d)

Fig. 9: Multi-spectral Landsat 8 satellite image: (a) Original image (Image $\left.e_{1}\right)$, (b) Portion of water region (Image $\left.e_{1 w}\right)$, (c) Portion of vegetation region $\left(\operatorname{Image}_{1 v}\right)$, (d) Portion of soil region $\left(\operatorname{Image}_{1 s}\right)$.

where $x_{i}$ represents the pixel intensity value.

3. Entropy measure: Entropy measures the average uncertainty of information in each selected band in order to extract maximum information content.

$$
\text { Entropy }=\frac{1}{\lambda} \sum_{i=1}^{\lambda}-\left(\sum_{j=1}^{k} P\left(I_{j}^{i}\right) \ln P\left(I_{j}^{i}\right)\right)
$$

where, $P\left(I_{j}^{i}\right)$ demonstrates the probability of reflectance distribution within a band and $\lambda$ is the total number of selected bands. The minimum entropy represents least uncertainty and better cloud clustered performance.

4. Variance of first spectral derivative (VFSD): The captured satellite image covers same geo-spatial region in each multi-spectral bands. This reduces the information redundancy in each band which is for- mullated in Eq. 14

$$
\begin{array}{r}
D(i, j)=\sum_{i=1}^{\lambda} \sum_{j=1}^{\lambda}\left\{\sum_{x, y=1,1}^{M, N}\left(I^{i}(x, y)-I^{j}(x, y)\right)\right\} \\
\operatorname{VFSD}^{N}=\sqrt{\text { variance }\left(\sum_{j=1}^{\lambda} D(:, j)\right)}
\end{array}
$$

where, $\mathrm{M} \times \mathrm{N}$ is the number of pixels in a satellite image and $I^{i}(x, y)$ its pixel intensity value of $i^{t h}$ multispectral band. The $D(i, j)$ measures the similarity among the information in each band. $D(i, j)$ with minimum value corresponds to the maximum similarity of information.

5. Coefficient of variation $(\mathrm{COV})$ : $\mathrm{COV}$ reports the variability in the similarity measure between the multi-spectral bands which formulated as,

$\operatorname{COV}=\frac{\sqrt{\sum_{i=1}^{\lambda}\left(\sum_{j=1}^{\lambda} D(i, j)-\overline{\sum_{j=1}^{\lambda} D(:, j)}\right)^{2}}}{\lambda^{-\frac{1}{2}} \times \overline{\sum_{j=1}^{\lambda} D(:, j)}}$

where, $\overline{\sum_{j=1}^{\lambda} D(:, j)}$ represents the similarity between the bands. The minimum value of $C O V$ consists 


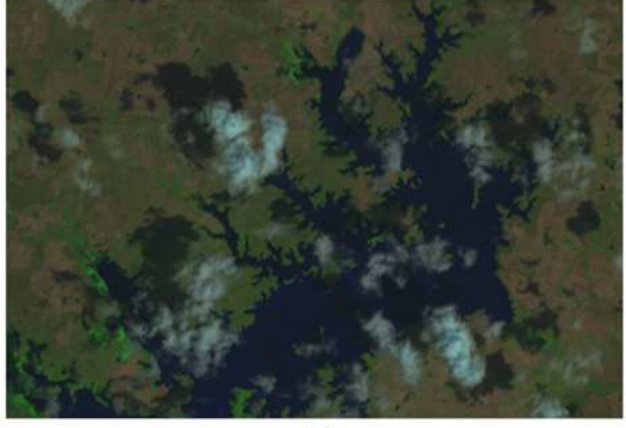

(a)

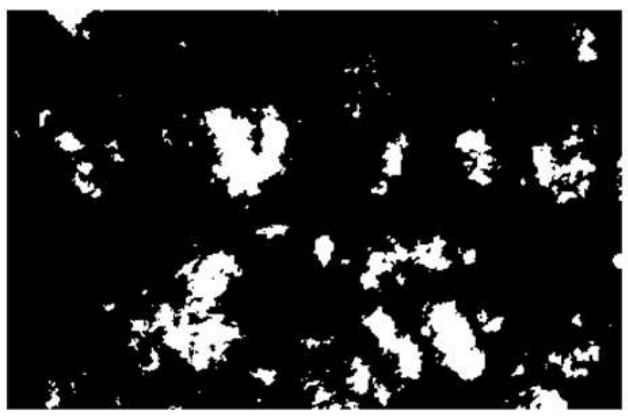

(c)

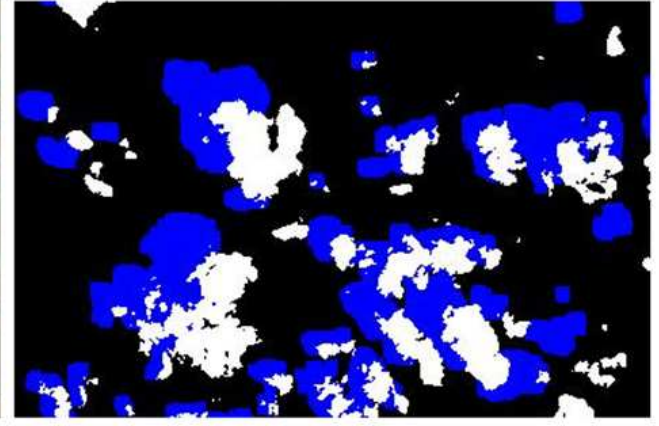

(b)

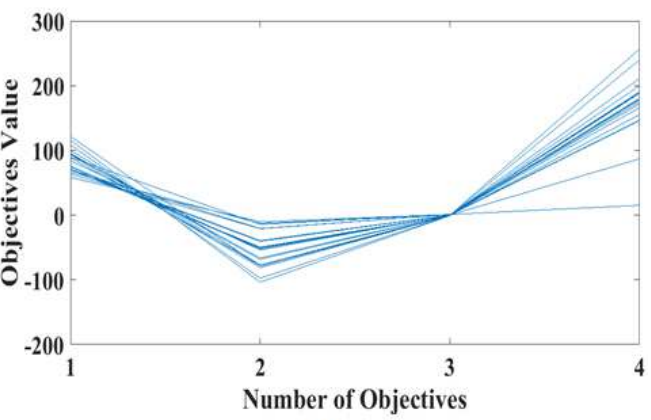

(d)

Fig. 10: Segmentation of cloud over water of $\operatorname{Image}_{1 w}$ : (a) original image (Image $e_{1 w}$ ), (b) quality band, (c) MOSSOII cloud clusering result, (d) parallel plot with reduced objective set.

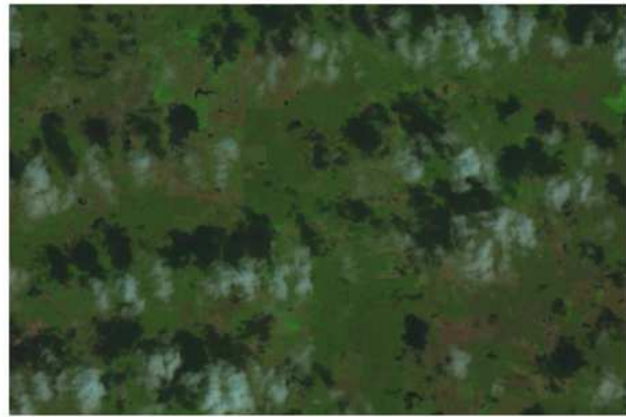

(a)

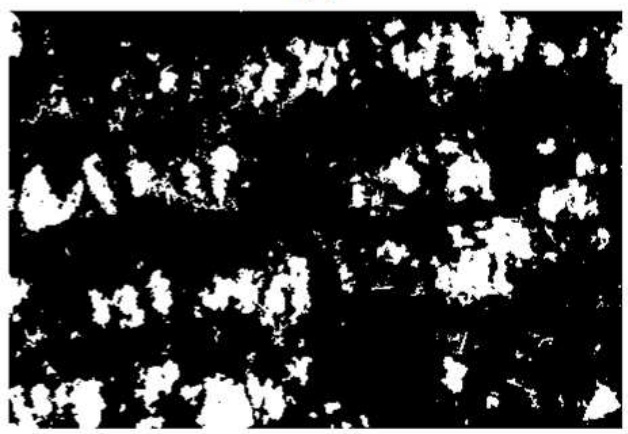

(c)

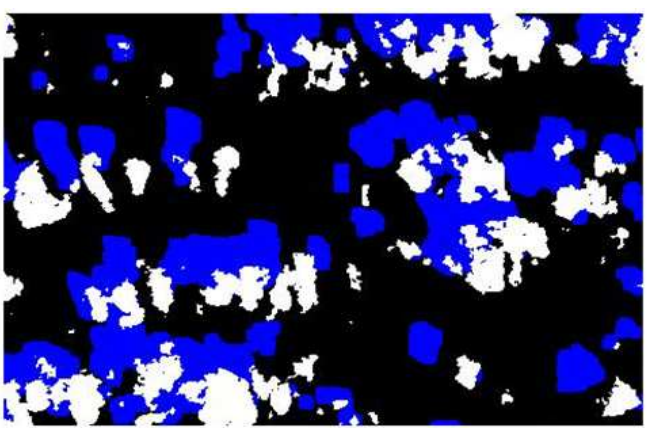

(b)

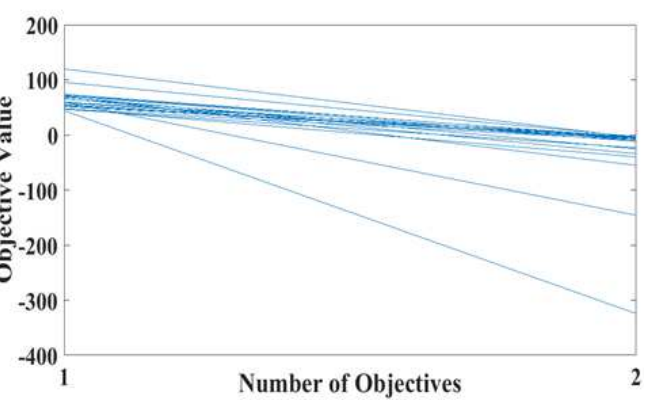

(d)

Fig. 11: Segmentation of cloud over vegetation of $\operatorname{Image}_{1 v}$ : (a) original image (Image $e_{1 v}$ ), (b) quality band, (c) MOSSO-II cloud clusering result, (d) parallel plot with reduced objective set. 


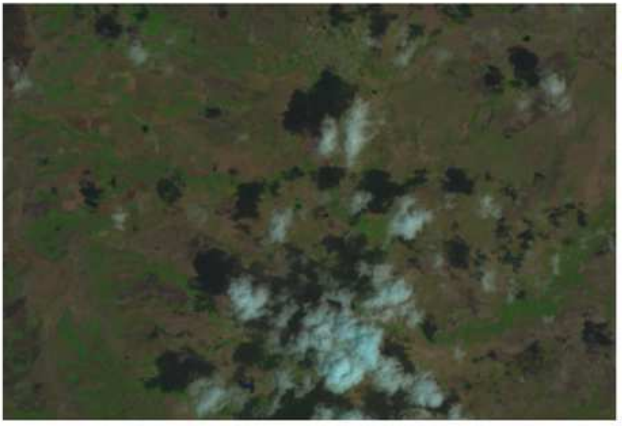

(a)

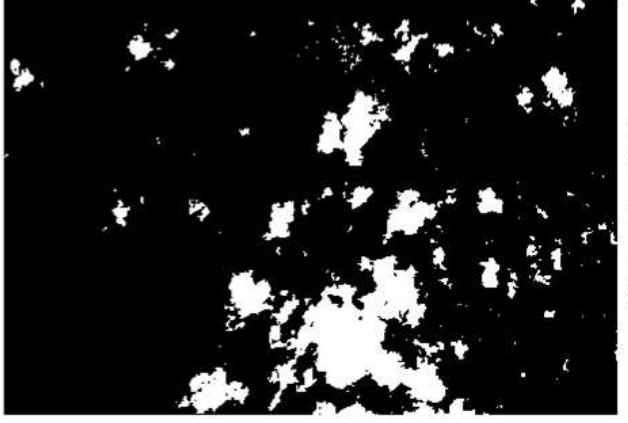

(c)

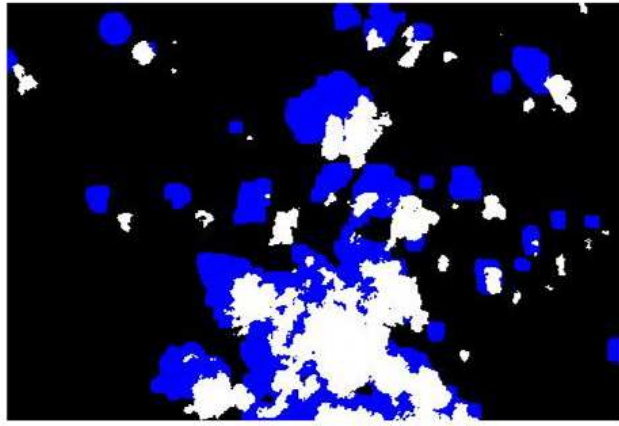

(b)

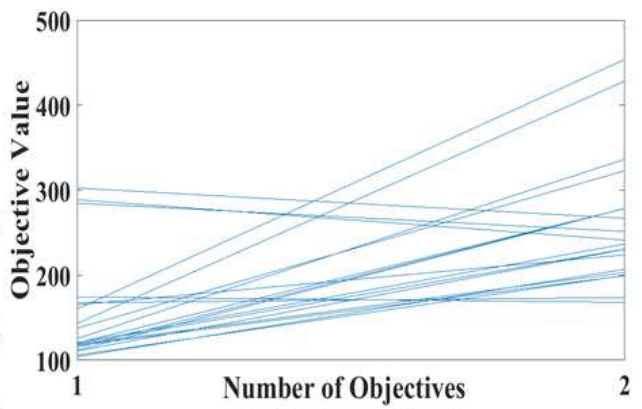

(d)

Fig. 12: Segmentation of cloud over soil of $\operatorname{Image}_{1 s}:(\mathrm{a})$ original image $\left(\right.$ Image $\left._{1 s}\right)$, (b) quality band, (c) MOSSO-II cloud clusering result, (d) parallel plot with reduced objective set.

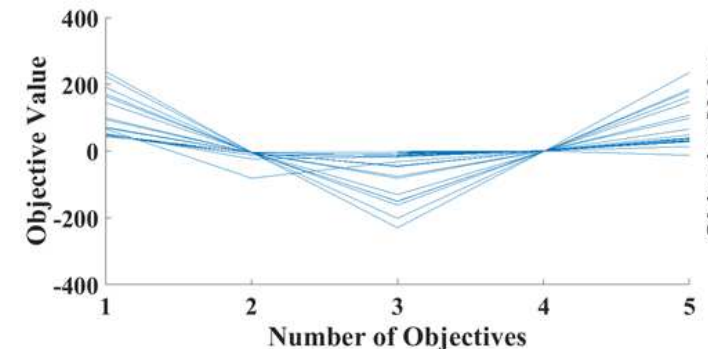

(a)

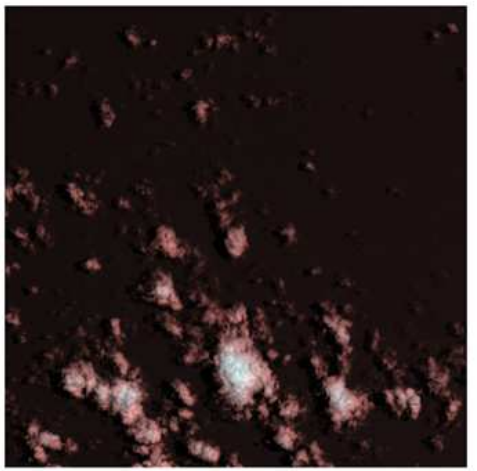

(c)

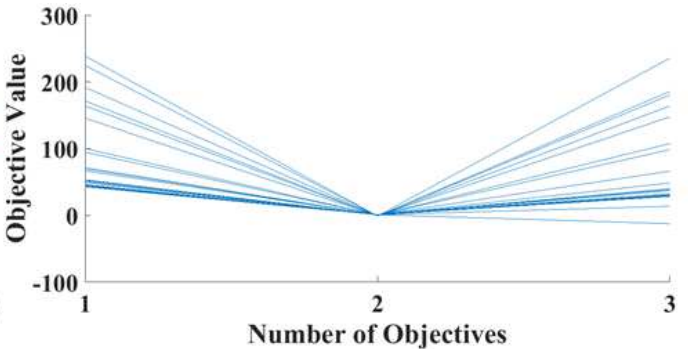

(b)

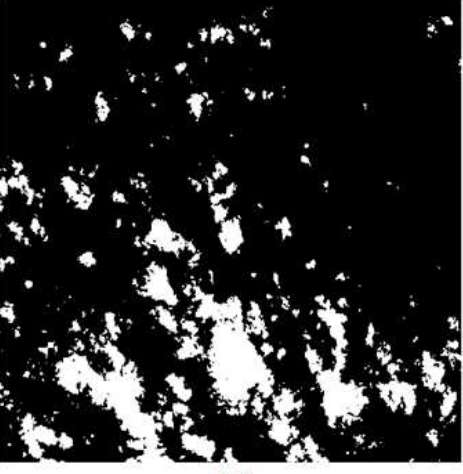

(d)

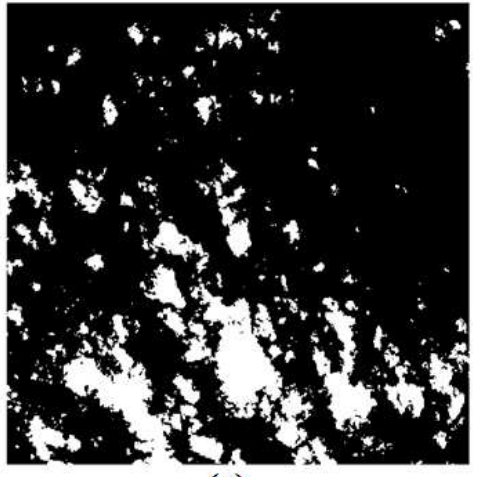

(e)

Fig. 13: Segmentation of cloud over water: (a) parallel coordinates of NSGA-III, (b) parallel coordinates of MOSSO, (c) Original image $\left(\operatorname{Image}_{2 w}\right)$, (d) NSGA-III clustering result, (e) MOSSO clustering result. 


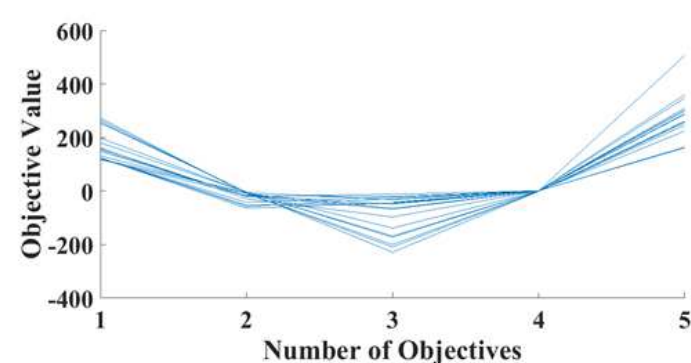

(a)

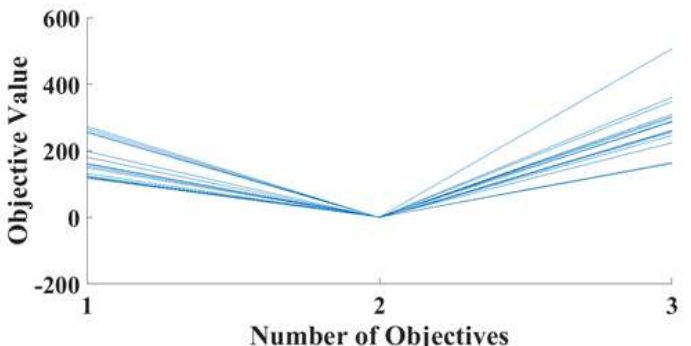

(b)

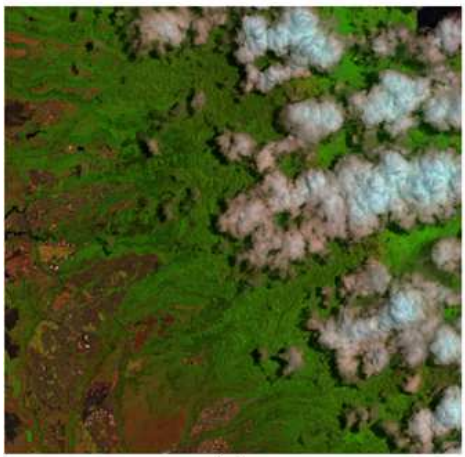

(c)

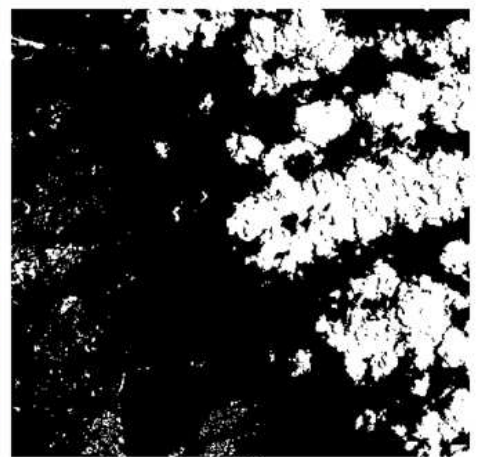

(d)

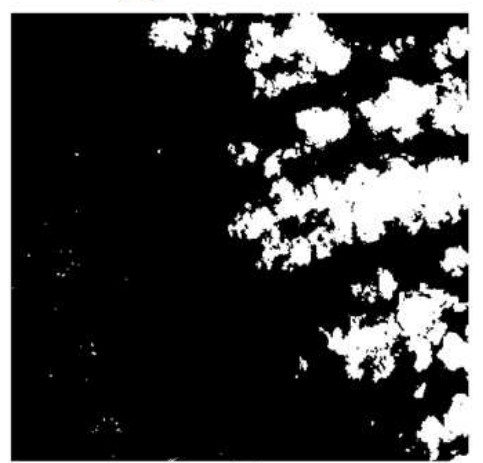

(e)

Fig. 14: Segmentation of cloud over vegetation: (a) parallel coordinates of NSGA-III, (b) parallel coordinates of MOSSO, (c) Original image $\left(\right.$ Image $\left._{2 v}\right)$, (d) NSGA-III clustering result, (e) MOSSO clustering result.

maximum similar information in each individual bands.

\subsection{Results for numeric satellite data}

The aim of this section is to determine the conceptual benefits of objective reduction technique to solve many-objective clustering problem.

\subsubsection{Experiment on water territory}

Fig. 10(d) reports the conflict essential objectives using the proposed MOSSO algorithm for Image $\operatorname{Im}_{1}$. The reduced objective set is further utilized to extract cloud contaminated region against water region which is shown in Fig. 10(c). Fig. 10(b) shows the quality band in which blue color pixels represent cloud shadow whereas white intensity pixels demonstrate cloud contaminated region. It is observed that clustered result using reduced objective set discriminates correct cloudy pixels with respect to quality band.

\subsubsection{Experiment on vegetation territory}

Fig. 11(a) shows Image $_{1 v}$ of multi-spectral satellite image. Fig. 11(d) represents most conflicting reduced objective set over delivered sample set. This is further utilized to extract cloudy pixels against cloud shadow and vegetation region. Fig. 11 (c) demonstrates the clustered result using the proposed approach in which white color intensity pixel shows cloudy pixel while black intensity are clear pixels.

\subsubsection{Experiment on soil territory}

Image $_{1 s}$ is a sub-part of original L8 satellite image which is shown in Fig. 12 (a). Fig. 12(c) represents cloud clustered result using the proposed MOSSO-II algorithm using conflict reduced objective-set (see Fig. 12(d)). It is observed that reduced objective set gives better clustered result against soil region over quality band shown in Fig. 12 (b).

\section{Experimental analysis with many-objective optimization algorithms}

In this section, the performance of the proposed MOSSO objective reduction technique to solve clustering problem in discriminating cloud contaminated region is done by comparing its result with the clustered result of many-objective $\theta$-NSGA-III algorithm. This is done by evaluating the performance of the compared algorithms on all the three territories (i.e., $\operatorname{Image}_{2 w}, \operatorname{Image}_{2 v}$, and Image $_{2 s}$ ) of Image $_{2}$. 


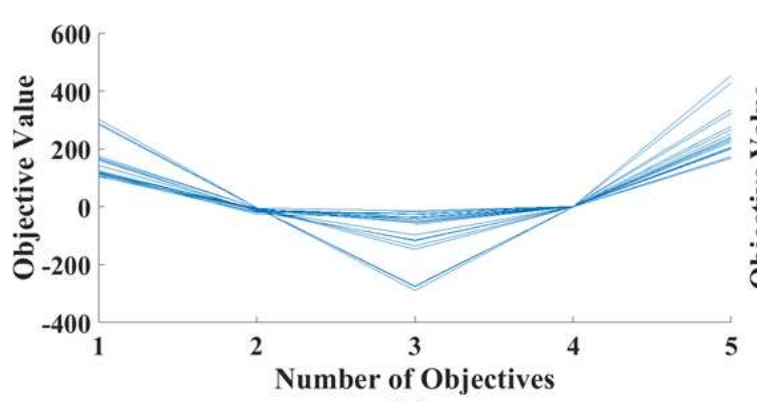

(a)

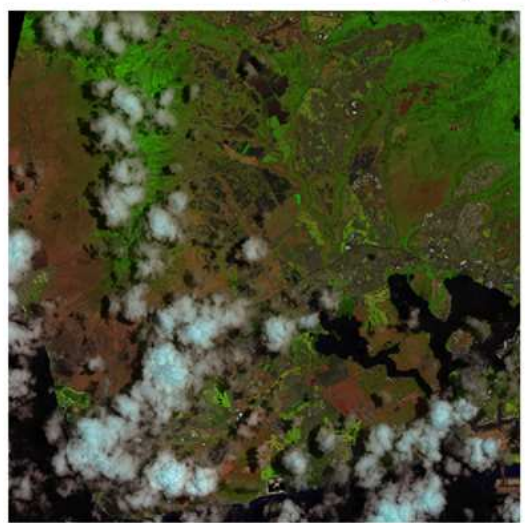

(c)

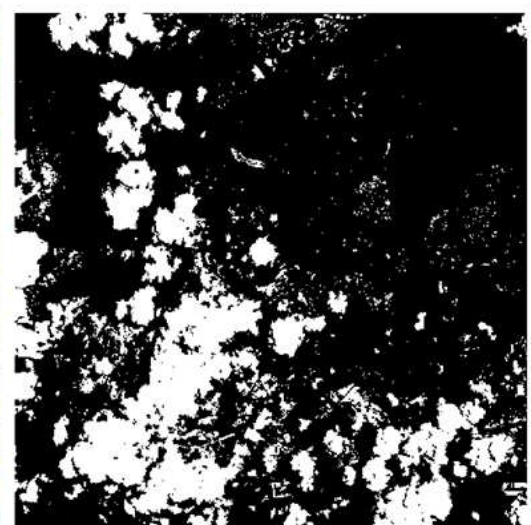

(d)

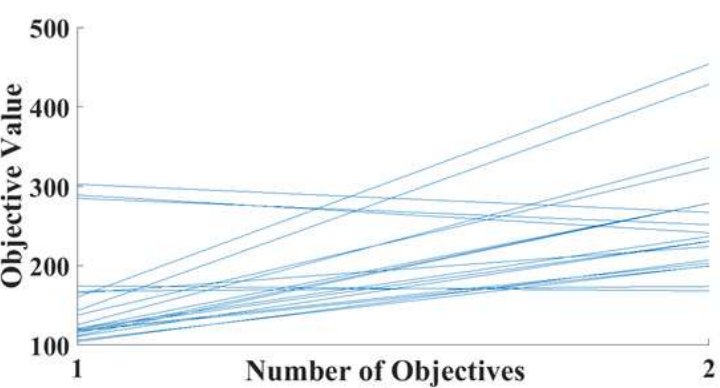

(b)

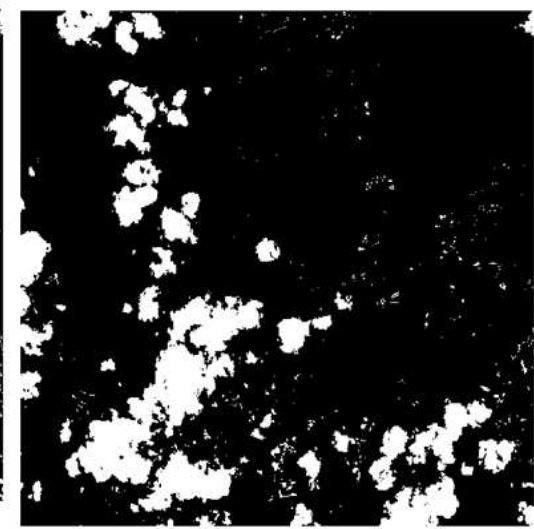

(e)

Fig. 15: Segmentation of cloud over soil: (a) parallel coordinates of NSGA-III, (b) parallel coordinates of MOSSO, (c) Original image $\left(\right.$ Image $\left._{1 s}\right)$, (d) NSGA-III clustering result, (e) MOSSO clustering result.

Table 9: Reduced objective set using MOSSO for Image $_{2}$.

\begin{tabular}{cccc}
\hline Image & $\delta_{1}$ & $\delta_{2}$ & Objective set \\
\hline Image $_{2 w}$ & 2.197 & 0.8161 & $\{\mathrm{f} 1, \mathrm{f} 3, \mathrm{f} 4, \mathrm{f} 5\}$ \\
Image $_{2 v}$ & 2.7447 & 0.598 & $\{\mathrm{f} 1, \mathrm{f} 2\}$ \\
Image $_{2 s}$ & 11.422 & 0.6762 & $\{\mathrm{f} 2, \mathrm{f} 3, \mathrm{f} 4\}$ \\
\hline
\end{tabular}

Table 10: Classification error percentage (\%) for L8 image, Image . $_{2}$

\begin{tabular}{ccccc}
\hline \multirow{2}{*}{ Method } & \multicolumn{2}{c}{ MOSSO } & \multicolumn{2}{c}{ NSGA-III } \\
\cline { 2 - 5 } & Mean & Std. Dev. & Mean & Std. Dev. \\
\hline Image $_{2 w}$ & $1.10 \mathrm{E}+01$ & $1.10 \mathrm{E}+01$ & $5.80 \mathrm{E}-01$ & $2.90 \mathrm{E}-01$ \\
Image $_{2 v}$ & $3.43 \mathrm{E}+00$ & $2.63 \mathrm{E}-01$ & $2.40 \mathrm{E}+00$ & $2.86 \mathrm{E}+00$ \\
Image $_{2 s}$ & $9.22 \mathrm{E}+00$ & $5.79 \mathrm{E}+00$ & $4.32 \mathrm{E}+00$ & $1.42 \mathrm{E}+00$ \\
\hline
\end{tabular}

\subsection{Experiment on water territory}

Fig. 13 (b) reports the parallel plot for Image $_{2 w}$ using the proposed objective reduction technique. Result indicates that obtained essential objectives are conflict objectives. This reduced objective set is further utilized to cluster cloud contaminated region over water surface in multi-spectral satellite image. It is ob- served from Fig. 13 (e) that the proposed algorithm gives competitive cloud clustering result over clustering result of benchmark NSGA-III (Fig. 13 (d)) using objective set shown in Fig. 13 (a). Therefore, the reduced objective set performs alike in terms of convergence and diversity over the solutions obtained with five objectives. 


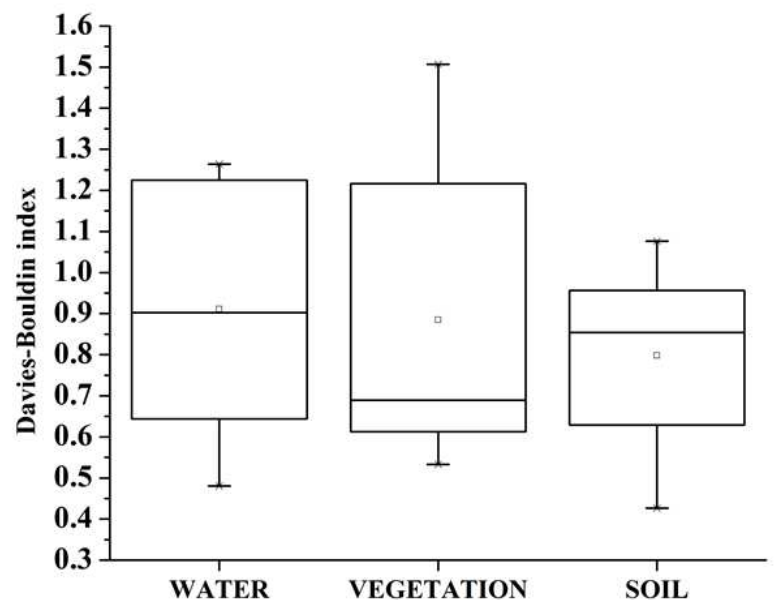

(a)

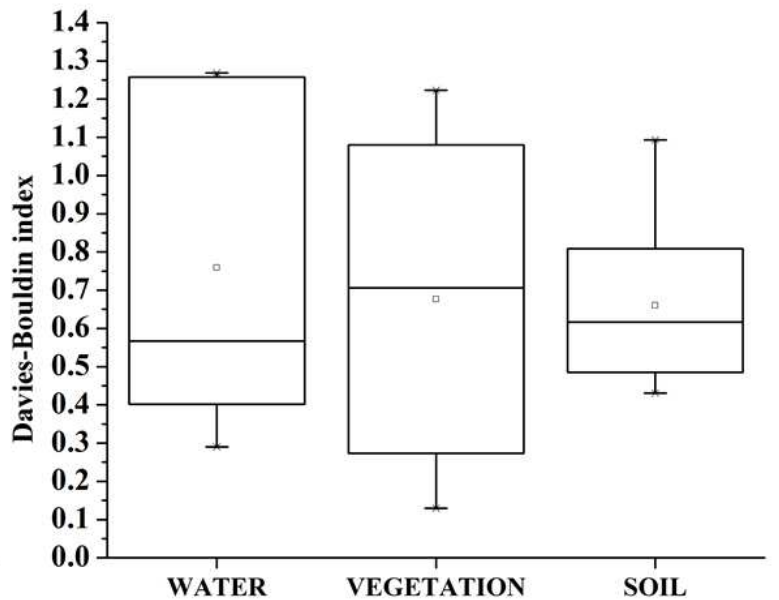

(b)

Fig. 16: Box plot of Davies-Bouldin index with 10 independent runs using: (a) NSGA-III and (b) MOSSO.

\subsection{Experiment on vegetation territory}

It is observed from Fig. 14 (d) that clustering result using NSGA-III mis-classifies non-existing cloudy pixels where soil region is present whereas the proposed approach separates it more effectively. This demonstrates the better convergence behavior of the proposed MOSSO algorithm with essential objectives. Figs. 114(a)-(b) show the parallel coordinate plot of NSGA-III and the proposed MOSSO algorithms which perform alike in terms of distribution of solutions. Therefore, it is observed that MOSSO maintains the convergence and diversity properties among the solutions for Image $_{2 v}$ image by removing redundant objectives from the sample-set.

\subsection{Experiment on soil territory}

The similar spectral property of soil and cloud makes difficult to distinguish cloud over soil territory. The proposed algorithm (Fig.15(e)) shows cloud segmented result equivalent to NSGA-III (Fig. 15(d)) over many lower regions with clear pixels. Fig. 15 (b) shows the better distribution of solutions with minimum essential objectives using MOSSO algorithm over supplied sample set which is shown in Fig. 15 (a).

Table 9 shows the result of reduced objective set using the proposed approach for each sub-part of Image $_{2}$. Here, reduced objective set is represented with corresponding clustering validity indices in order to validate the clustering accuracy using the proposed objective reduction technique.

\subsection{Validation techniques}

\subsubsection{Classification error percentage (CEP)}

The classification error percentage (CEP) gives the information regarding mis-classified cloudy pixels from the obtained result. It means minimum value of CEP gives better classification result.The CEP is mathematically formulated as,

CEP $=\frac{\text { Mis-classified cloudy pixels }}{n} \times 100 \%$

where, $\mathrm{n}$ is the total number of pixels. Table 10 gives the CEP value on database discussed in previous section. It is observed that many-objective NSGA-III algorithm shows significant improvement in discrimination of cloud over Image $e_{2 w}$, Image $e_{2 v}$ and Image Is $_{2} \mathrm{im}$ ages in terms of minimum value of CEP as compared to MOSSO approach. However, least difference is ob-

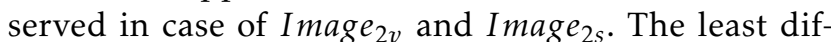
ference is observed in CEP value with MOSSO using reduced objective function over NSGA-III with entire objective set.

Reduction in objective function hampers the accuracy which results into larger CEP value. Therefore, larger CEP values using MOSSO algorithm clearly show weak Pareto front approximation and better Pareto front representation. 


\subsubsection{Davies-Bouldin (DB) index}

The Davies-Bouldin (DB) index is used to evaluate clustering algorithm which is equated in Eq. 17

DBindex $=\frac{1}{K} \sum_{i=1}^{K} \max _{i \neq j}\left\{\frac{\Delta\left(C_{i}\right)+\Delta\left(C_{j}\right)}{d\left(C_{i}, C_{j}\right)}\right\}$

where $\Delta\left(C_{i}\right)$ measures the compactness of $C_{i}$ cluster and $d\left(C_{i}, C_{j}\right)$ shows the distance between the centroids $C_{i}$ and $C_{j}$. The average value of DB index is computed after ten independent runs to show the superiority of the proposed MOSSO algorithm. Lower value of DB index indicates the better clustering performance. Fig. 16 reports that mean value of DB index of cloud detection using NSGA-III against water, vegetation and soil is $0.9,0.68$ and 0.9 , respectively. However, mean DB index value of cloud detection using MOSSO against water, vegetation and soil is $0.55,0.7$ and 0.65 , respectively with 10 independent run. This demonstrates the better performance of proposed approach using reduced objective set to handle many-objective problems. The result also demonstrates that proposed approach gives quite divergent but minimum average value in all cases. The performance of NSGA-III algorithm is found to be similar to the proposed approach except for vegetation $\left(\operatorname{Image}_{2 v}\right.$ ) where their Davies-Bouldin index is observed to be larger.

\section{Conclusion}

In this article, a study on evolutionary multi-objective technique is conducted for objective reduction to solve MaOPs. In the present work, MOSSO is used as multiobjective search problem to view objective reduction with the aim to preserve correlation structure in obtained original objective set. The proposed approach involves two conflict multi-objective functions and environmental selection method to get trade-off among the objectives and obtain an optimal solution that offers a decision support to select essential objectives. Furthermore, a detailed analysis of MOSSO is provided to reveal the strengths and weaknesses of the approach on various benchmark MaOPs. Extensive analysis is further conducted over multi-spectral satellite images to detect clouds in the presence of different territories of earth. The comparison of MOSSO is further evaluated against many-objective NSGA-III algorithm in terms of CEP and Davies-Bouldin index which demonstrates the potential of the proposed approach with essential objective set against original objective set.

As a scope of further research, proposed MOSSO objective reduction approach can be effectively applied in various real-life many-objective optimization problems. The MOSSO objective reduction method to handle constraints based many-objective test problems needs to be explored. The authors are presently working towards these directions.

\section{Compliance with ethical standards}

Conflict of interest The authors declares that they have no conflicts of interest.

Research grants from funding agencies No grant

Human participants or animals rights This article does not contain any studies with human participants or animals performed by any of the authors.

Informed consent Informed consent was obtained from all individual participants included in the study.

\section{References}

Babu B, Gujarathi AM (2007) Multi-objective differential evolution (mode) algorithm for multi-objective optimization: parametric study on benchmark test problems. Journal on Future Engineering and Technology 3(1):47-59

Berendes T, Kuo K, Logar A, Corwin E, Welch R, Baum B, Pretre A, Weger R (1999) A comparison of paired histogram, maximum likelihood, class elimination, and neural network approaches for daylight global cloud classification using avhrr imagery. Journal of Geophysical Research: Atmospheres 104(D6):61996213

Brockhoff D, Zitzler E (2007) Improving hypervolume-based multiobjective evolutionary algorithms by using objective reduction methods. In: 2007 IEEE congress on evolutionary computation, IEEE, pp 2086-2093

Brockhoff D, Zitzler E (2009) Objective reduction in evolutionary multiobjective optimization: Theory and applications. Evolutionary computation 17(2):135-166

Cai X, Li Y, Fan Z, Zhang Q (2014) An external archive guided multiobjective evolutionary algorithm based on decomposition for combinatorial optimization. IEEE Transactions on Evolutionary Computation 19(4):508-523

Chand S, Wagner M (2015) Evolutionary manyobjective optimization: A quick-start guide. Surveys in Operations Research and Management Science 20(2):35-42 
Cheng R, Jin Y, Olhofer M, Sendhoff B (2016) A reference vector guided evolutionary algorithm for many-objective optimization. IEEE Transactions on Evolutionary Computation 20(5):773-791

Coakley Jr JA, Bretherton FP (1982) Cloud cover from high-resolution scanner data: Detecting and allowing for partially filled fields of view. Journal of Geophysical Research: Oceans 87(C7):4917-4932

Coello CAC, Pulido GT, Lechuga MS (2004) Handling multiple objectives with particle swarm optimization. IEEE Transactions on evolutionary computation 8(3):256-279

Corne DW, Knowles JD, Oates MJ (2000) The pareto envelope-based selection algorithm for multiobjective optimization. In: International conference on parallel problem solving from nature, Springer, pp 839-848

Deb K, Jain H (2013) An evolutionary many-objective optimization algorithm using reference-point-based nondominated sorting approach, part i: solving problems with box constraints. IEEE Transactions on Evolutionary Computation 18(4):577-601

Deb K, Saxena D (2006) Searching for pareto-optimal solutions through dimensionality reduction for certain large-dimensional multi-objective optimization problems. In: Proceedings of the World Congress on Computational Intelligence (WCCI-2006), pp 33523360

Deb K, Pratap A, Agarwal S, Meyarivan T (2002a) A fast and elitist multiobjective genetic algorithm: Nsga-ii. IEEE transactions on evolutionary computation 6(2):182-197

Deb K, Thiele L, Laumanns M, Zitzler E (2002b) Scalable multi-objective optimization test problems. In: Proceedings of the 2002 Congress on Evolutionary Computation. CEC'02 (Cat. No. 02TH8600), IEEE, vol 1, pp 825-830

Ding R, Dong $\mathrm{Hb}$, Yin Gs, Sun J, Yu Xd, Feng Xb (2021) An objective reduction method based on advanced clustering for many-objective optimization problems and its human-computer interaction visualization of pareto front. Computers \& Electrical Engineering 93:107266

Erickson M, Mayer A, Horn J (2001) The niched pareto genetic algorithm 2 applied to the design of groundwater remediation systems. In: International Conference on Evolutionary Multi-Criterion Optimization, Springer, pp 681-695

de Freitas AR, Fleming PJ, Guimarães FG (2015) Aggregation trees for visualization and dimension reduction in many-objective optimization. Information Sciences 298:288-314
Gupta R, Nanda S (2019a) Vector-angle penalised nsga-iii to solve many-objective optimisation problems. Electronics Letters 55(4):198-200

Gupta R, Nanda SJ (2019b) A binary nsga-iii for unsupervised band selection in hyper-spectral satellite images. In: 2019 IEEE Congress on Evolutionary Computation (CEC), IEEE, pp 522-529

Gupta R, Nanda SJ, Shukla UP (2019) Cloud detection in satellite images using multi-objective social spider optimization. Applied Soft Computing 79:203226

rey Horn J, Nafpliotis N, Goldberg DE (1994) A niched pareto genetic algorithm for multiobjective optimization. In: Proceedings of the first IEEE conference on evolutionary computation, IEEE world congress on computational intelligence, Citeseer, vol 1, pp 82-87

James J, Li VO (2015) A social spider algorithm for global optimization. Applied Soft Computing 30:614-627

Jensen JR (2009) Remote sensing of the environment: An earth resource perspective 2/e. Pearson Education India

Knowles JD, Corne DW (2000) Approximating the nondominated front using the pareto archived evolution strategy. Evolutionary computation 8(2):149172

Liu SC, Zhan ZH, Tan KC, Zhang J (2021) A multiobjective framework for many-objective optimization. IEEE Transactions on Cybernetics

López Jaimes A, Coello Coello CA, Chakraborty D (2008) Objective reduction using a feature selection technique. In: Proceedings of the 10th annual conference on Genetic and evolutionary computation, ACM, pp 673-680

Ma L, Huang M, Yang S, Wang R, Wang X (2021) An adaptive localized decision variable analysis approach to large-scale multiobjective and manyobjective optimization. IEEE Transactions on Cybernetics

Maktav D (2009) Remote Sensing for a Changing Europe: Proceedings of the 28th Symposium of the European Association of Remote Sensing Laboratories, Istanbul, Turkey, 2-5 June 2008. IOS Press

Nanda SJ, Panda G (2014) A surve on nature inspired meta heuristic algorithms for partitional clustering. Swarm and Evolutionary Computation 16(2):1-18

Saxena DK, Duro JA, Tiwari A, Deb K, Zhang Q (2012) Objective reduction in many-objective optimization: Linear and nonlinear algorithms. IEEE Transactions on Evolutionary Computation 17(1):77-99

Singh HK, Isaacs A, Ray T (2011a) A pareto corner search evolutionary algorithm and dimensional- 
ity reduction in many-objective optimization problems. IEEE Transactions on Evolutionary Computation 15(4):539-556

Singh HK, Isaacs A, Ray T (2011b) A pareto corner search evolutionary algorithm and dimensionality reduction in many-objective optimization problems. IEEE Transactions on Evolutionary Computation 15(4):539-556

Srinivas N, Deb K (1994) Muiltiobjective optimization using nondominated sorting in genetic algorithms. Evolutionary computation 2(3):221-248

Tanigaki Y, Nojima Y, Ishibuchi H (2016) Metaoptimization based multi-objective test problem generation using wfg toolkit. In: 2016 IEEE Congress on Evolutionary Computation (CEC), IEEE, pp 2768-2775

Wang H, Yao X (2016) Objective reduction based on nonlinear correlation information entropy. Soft Computing 20(6):2393-2407

Xiang Y, Zhou Y, Li M, Chen Z (2016) A vector anglebased evolutionary algorithm for unconstrained many-objective optimization. IEEE Transactions on Evolutionary Computation 21(1):131-152

Xue B, Zhang M, Browne WN, Yao X (2015) A survey on evolutionary computation approaches to feature selection. IEEE Transactions on Evolutionary Computation 20(4):606-626

Yuan Y, Ong YS, Gupta A, Xu H (2017) Objective reduction in many-objective optimization: evolutionary multiobjective approaches and comprehensive analysis. IEEE Transactions on Evolutionary Computation 22(2):189-210

Zhang Q, Li H (2007) Moea/d: A multiobjective evolutionary algorithm based on decomposition. IEEE Transactions on evolutionary computation 11(6):712-731

Zitzler E, Thiele L (1999) Multiobjective evolutionary algorithms: a comparative case study and the strength pareto approach. IEEE transactions on Evolutionary Computation 3(4):257-271

Zitzler E, Laumanns M, Thiele L (2001) Spea2: Improving the strength pareto evolutionary algorithm. TIK-report 103 